\title{
Industrial Verification and Research Development of Lime-Gypsum Fertilizer Granulation Method
}

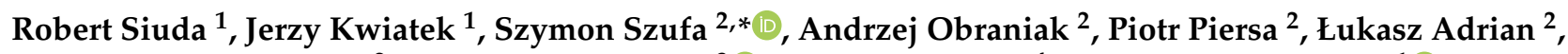 \\ Remigiusz Modrzewski ${ }^{2}$, Katarzyna Ławińska ${ }^{3}{ }^{\circledR}$, Krzysztof Siczek ${ }^{4}$ and Tomasz P. Olejnik ${ }^{1}$ (D) \\ 1 Faculty of Biotechnology and Food Science, Lodz University of Technology, Wolczanska 171/173, \\ 90-924 Lodz, Poland; robert.siuda@dokt.p.lodz.pl (R.S.); jerzy.kwiatek@dokt.p.lodz.pl (J.K.); \\ tomasz.olejnik@p.lodz.pl (T.P.O.) \\ 2 Faculty of Process and Environmental Engineering, Lodz University of Technology, Wolczanska 213, \\ 90-924 Lodz, Poland; andrzej.obraniak@p.lodz.pl (A.O.); piotr.piersa@p.lodz.pl (P.P.); \\ lukasz.adrian@p.lodz.pl (Ł.A.); remigiusz.modrzewski@p.lodz.pl (R.M.) \\ 3 Łukasiewicz Research Network-Institute of Leather Industry, Zgierska 73, 91-462 Lodz, Poland; \\ k.lawinska@ips.lodz.pl \\ 4 Faculty of Vehicles and Fundamentals of Machine Design, Lodz University of Technology, \\ Stefanowskiego 1/15, 90-537 Lodz, Poland; krzysztof.siczek@p.lodz.pl \\ * Correspondence: szymon.szufa@p.lodz.pl; Tel.: +48-606-134-239
}

check for updates

Citation: Siuda, R.; Kwiatek, J.; Szufa, S.; Obraniak, A.; Piersa, P.; Adrian, Ł.; Modrzewski, R.; Ławińska, K.; Siczek, K.; Olejnik, T.P. Industrial Verification and Research Development of Lime-Gypsum Fertilizer Granulation Method. Minerals 2021, 11, 119. https:// doi.org/10.3390/min11020119

Received: 23 December 2020

Accepted: 22 January 2021

Published: 26 January 2021

Publisher's Note: MDPI stays neutral with regard to jurisdictional claims in published maps and institutional affiliations.

Copyright: (c) 2021 by the authors. Licensee MDPI, Basel, Switzerland. This article is an open access article distributed under the terms and conditions of the Creative Commons Attribution (CC BY) license (https:/ / creativecommons.org/licenses/by/ $4.0 /)$.
Abstract: This work concerns non-pressure granulation of mineral materials used for the production of agricultural fertilizers for soil deacidification. In order to expand the product range of Nordkalk Poland sp. z o. o. located in Poland, the granulation conditions of the gypsum-lime mix were examined with the use of various granulation methods. The processed mixture was Jurassic lime flour mined in the Sławno mine (Poland) and waste gypsum (sulfogypsum) obtained from the largest coal-fired power plant in the EU, Bełchatów Power Plant (Poland). This paper presents the results of the optimization of the gypsum-lime fertilizer granulation process. The results of the study of granulation of gypsum-lime mixture realized in one-stage technology in a disc granulator were compared with the effects of two-stage agglomeration. During the research, a mixture (in a 1:1 ratio) of waste sulfogypsum and lime flour was used. Such a weight ratio provides maximum use of the sulfogypsum waste while maintaining good mechanical properties of the granulate. The granulated bed was moistened with a lignosulfonate solution. The process was carried out periodically. After the experiment, the grain composition of the granulate obtained was determined and tests were performed to determine the strength of the product. The test results were compared with analogous ones obtained during granulation with the use of molasses (waste from sugar production). The results obtained were verified during a trial carried out on an industrial scale.

Keywords: sulfogypsum; limestone flour; lignosulfonate; molasses; disc granulation; waste as fertilizers

\section{Introduction}

The term non-pressure granulation is understood as the production of solid particles of appropriate shape, dimensions, and physicochemical properties, with an increase in the size of the resulting granules by nucleation [1,2], surrounding granules [3,4], or coalescence [5,6]. Obtaining the desired product including agricultural fertilizers can be done in many different ways and the process itself can be combined with other unit operations. It should be understood that the entire process, especially on an industrial scale, does not consist of only one stage, which is the formation of granules, but is the sum of many technological processes, starting from the preparation of raw materials and ending with the separated finished product. This happens especially when the aim of the process is to produce agricultural fertilizer, the main component of which is a waste material with favorable properties for soil fertilization, e.g., it contains calcium compounds [7], sulfur [8], 
or organic carbon [9]. Such material usually requires additional technological operations adjusting its properties to the non-pressure agglomeration process. In the case of granular materials, it must have an appropriate granulometric composition, moisture, bulk density, and chemical composition, while it should be remembered that the waste materials used in the granulation process can be either loose materials or those that can be crushed $[10,11]$ and sieved [12,13] to a preferred form, and liquids that serve as binders [14]. Examples of waste bulk materials that can be used in the granulation of agricultural fertilizers are phosphogypsum [15] and sulfogypsum [16], post-saturation mud [17] and ashes resulting from biomass combustion [18], as well as maize straw [19], millet and cane [20], and coal ashes [21]. Non-pressure granulation of mineral materials can be performed in a disc [22], drum [23], in a batch [24], and in continuous operation [25], vibrating [26], mixing [27], in a fluid bed [28,29], as well as in continuous and multi-stage technology, which uses combinations of the above-mentioned devices. Depending on the choice of the process variant, the wetting liquid for the processed bed can be supplied before the granulation process, during the process in the form of one portion [30], or continuously with precisely defined moistening parameters [31].

The non-pressure granulation process is influenced by the parameters of wetting [32], parameters characterizing the granulated raw material [33], the liquid used to moisten the granulated bed [34], and the applied granulation technologies [35].

Sulfogypsum used in the research came from the flue gas desulphurization process at the Bełchatów Power Plant, and the limestone powder from the Mineral Raw Materials Mine of the Nordkalk Sławno Plant. The limestone flour was characterized by moisture content of $0.3 \%$ and a grain size below $300 \mu \mathrm{m}$, while the sulfogypsum had a moisture content of $15 \%$, and its grain size did not exceed $500 \mu \mathrm{m}$. The purpose of composing a mixture with the appropriate composition was to equalize its humidity. This was necessary due to the difficulties encountered in granulating wet gypsum. Preliminary studies have shown that when granulating very wet materials, they agglomerate before the moisturizing liquid is supplied to them. As a result of the lack of integrating substances, unstable granules are then formed, which are destroyed in subsequent technological operations.

Material moisture content was determined from formula (1).

$$
w=\frac{m_{w}}{m_{s}} \times 100 \%
$$

where: $w$-raw material moisture; $m_{w}$-water mass contained in the raw material; $m_{s}-$ mass of dry material.

All the above-mentioned factors have an impact on the one hand on the dynamics of the processed bed and, consequently, on the number of collisions of particles making up the product and on the granulation mechanisms (nucleation, encapsulation, coalescence, abrasion, and compaction) responsible for the formation of stable agglomerates. At the same time, during the disc or drum granulation, apart from the agglomeration process, the impact of the raw material bed takes place, leading to the disintegration of the newly formed granules. The destructive effect of the raw material and the resulting granules slows down the kinetics of the process, increasing the unit energy inputs [36].

Granular mineral fertilizers, including calcium fertilizers, are obtained by agglomeration by mixing components in specific proportions, which result from the assumed composition, and by moistening such dusty components with a binding liquid [37]. Such a liquid is most often water [38] or aqueous solutions of substances such as gelatin, polymers, resins, starch, glues, sugars, salts, or molasses [39,40]. This type of process can be carried out in one-stage and two-stage technology and may also apply to products other than agricultural fertilizers [41,42]. There is a known method [43] of agglomeration of dust raised from kilns intended for the firing of cement clinker, fillers, powdery fertilizers, ashes from electrostatic precipitators, and dyes, using drum or disc granulators in which agglomeration by surrounding occurs and which is carried out in two stages. The first stage of granulation (nucleation of agglomerates from the powdery raw material and the 
wetting liquid) takes place outside the granulator, most often in a two-shaft or single-shaft blade mixer, while the size of the embryos and their spherical shapes increase as a result of encapsulation, which is carried out in a disk granulator or drum.

A similar method of granulation [44] with the use of a granulating liquid concerning powdery materials, especially fertilizers, is also performed in the two-stage granulation technology. The first step of the process is carried out in a paddle mixer. The raw material is mixed quite intensively by adding a liquid with a temperature of approx. $60^{\circ} \mathrm{C}$. Agglomerates of 1-6 millimeters in size are obtained, characterized by a dense structure and a moisture content of $6 \%$. In a second step in the process, the previously formed granules become spherical in shape as a result of enveloping mechanisms in the granulating drum or plate. Water, a suspension or an aqueous solution of the ingredients to be granulated as well as a solution of sodium salt, starch, molasses, or carboxymethyl cellulose with a concentration of more than $3 \%$ were used as the wetting liquid. There are also known [45-47] methods of granulating Jurassic lime flour or a mixture of lime flour, dolomite, chalk, and sulphogypsum carried out in mixing, plate, and drum granulators, in which water solutions of sugar and molasses are used to moisten such mixtures. Despite numerous technologies for the production of granulated mineral fertilizers described in the literature which use sugar, molasses, or other sugar production waste as a binder, there is a need to optimize and improve the parameters of the agglomeration process, improve the functional properties of the fertilizers obtained, and take into account economic factors in industrial production. An additional problem that needs to be solved in the course of further research is the issue of the storage of fertilizers produced with the use of sugar or ingredients containing sugar. Such fertilizers can become moldy during storage, which forces producers to look for a different binder. This is the case when storage takes place during the wet season. The selected substitute should, therefore, allow the production of fertilizer with the same or similar advantages as fertilizers made with sugars and at the same time be resistant to fungi. The use of waste material such as sulfogypsum or molasses for the production of fertilizers allows for the rational management of this waste and has a positive effect on the quality of the soil by increasing the content of calcium and other minerals contained in it. In the past, a common problem was that the mechanical strength of the granules was too low, which caused problems in the transport, dosing, and spreading of fertilizers. The granulated material was easily crushed and, as a result, dusted. The spreaders used in agriculture (e.g., disc spreaders) require relatively even graining of the fertilizer for proper operation. Therefore, methods of obtaining just such a granulate are being sought.

The aim of this work was:

1. to demonstrate the possibility of non-pressure granulation of gypsum-lime mixes with the use of lignosulfonate,

2. to compare the effects of granulation of calcium-gypsum mixtures realized in the disc and two-stage granulation technology,

3. to compare the effects of granulation of calcium-gypsum mixtures with the use of various moisturizing liquids,

4. to demonstrate the usefulness (despite high humidity) of waste gypsum obtained from the flue gas desulphurization process as a raw material for the production of granular agricultural fertilizer,

5. to verify the research results obtained by implementing the process on an industrial scale.

\section{Experimental Part}

\subsection{Apparatus and Research Methodology}

This paper compares two methods of granulating a mixture of waste gypsum (sulfogypsum) and limestone flour. In the first method (whose successive attempts are marked in this work with Arabic numerals) the process was carried out in a disk granulator, in the second two-stage method (whose individual samples are marked with Roman numerals), 
the raw material was nucleated in a mixing granulator, and then the pre-agglomerated bed was granulated in a disk apparatus. The granulation tests of the mixture of sulfogypsum and limestone powder according to the first method were carried out in a laboratory disc granulator as in Figure 1 with the disc diameter $D=500 \mathrm{~mm}$.

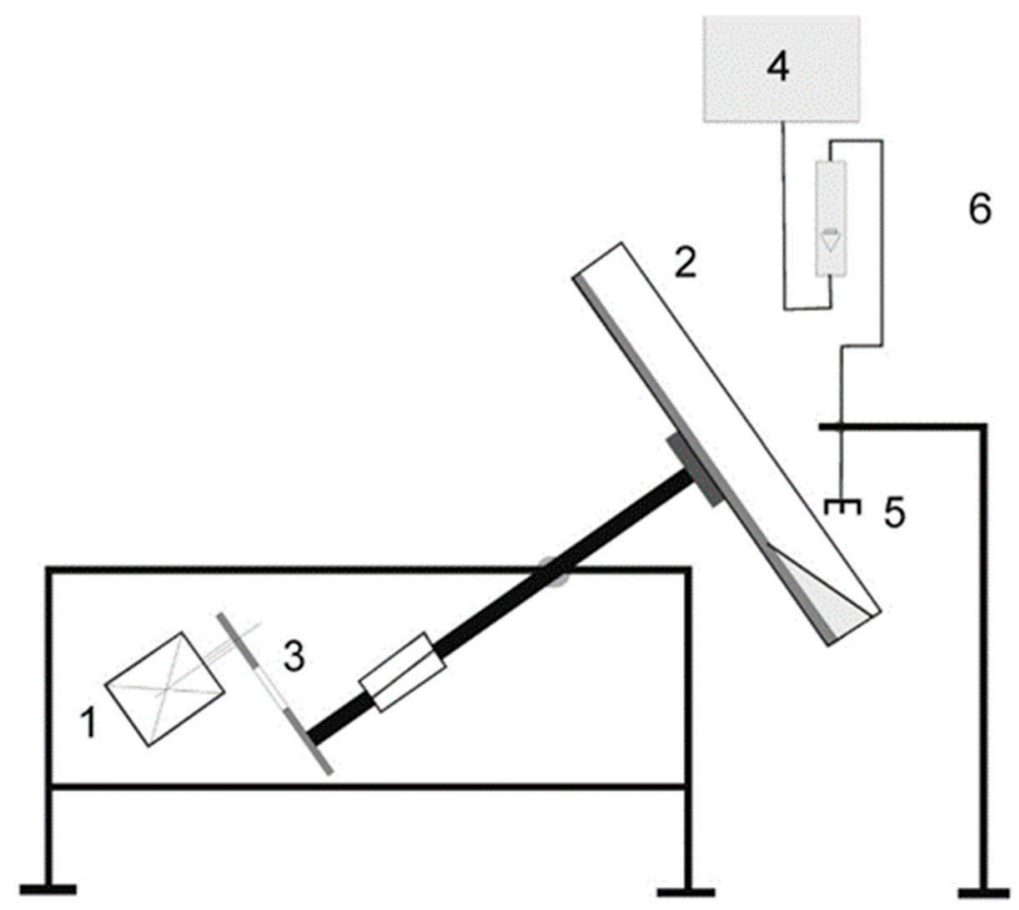

Figure 1. Disc granulator, design, and execution by Lodz University and Technology. 1. geared motor; 2. granulation plate; 3. Inverter; 4. tank for binding liquid; 5. Sprinkler; 6. rotameter.

Disc tilt angle $\alpha$ was $45^{\circ}$. Each test was carried out at a rotational speed of $12 \mathrm{rpm}$. The construction of the granulator permits changes to be made in the diameter of the disc in steps, the angle of its inclination, and in smoothing the rotational speed within a range of 0-50 $\mathrm{rpm}$. The process parameters characterizing the disc granulation tests (first method) are presented in Table 1. The moisturizing (binding liquid) in both methods was a $20 \%$ aqueous solution of lignosulfonate.

Table 1. Parameters of disc granulation (first method).

\begin{tabular}{|c|c|c|c|c|}
\hline \multirow{2}{*}{ Sample No. } & Mass of the Solution & Granulation Time & Stream Type & Concentration Lignosulfonate of the Binder \\
\hline & g & $\min$ & - & $\%$ \\
\hline 1 & 70 & 12 & continuous & 20 \\
\hline 2 & 125 & 6 & continuous & 20 \\
\hline 3 & 100 & 6 & continuous & 20 \\
\hline 4 & 80 & 12 & continuous & 20 \\
\hline 5 & 70 & 6 & vapor & 20 \\
\hline 6 & 150 & 6 & vapor & 20 \\
\hline 7 & 90 & 6 & diffused & 20 \\
\hline 8 & 80 & 6 & diffused & 20 \\
\hline 9 & 110 & 6 & diffused & 20 \\
\hline 10 & 125 & 6 & diffused & 20 \\
\hline
\end{tabular}

During the experiments, the mixture of raw materials was moistened with a $20 \%$ water solution of magnesium lignosulfonate. In order to moisturize, there was $90 \mathrm{~g}$ of dry weight lignosuldonate per $1000 \mathrm{~g}$ of solution weight. The granulation time was variable and amounted to $6 \mathrm{~min}$ for trials 2, 3, 5, 6, 7, 8, 9, 10, and $12 \mathrm{~min}$ for trials 1 and 4 . During the 
main tests, the influence of the spray type on the course of the process was also examined, distinguishing between a continuous stream, a dispersed stream, and a mist-Figure 2 . After completion of the granule forming process, the granulate obtained was dried at a temperature of $65^{\circ} \mathrm{C}$ for $24 \mathrm{~h}$. A sieve analysis was performed using sieves of $1 ; 2 ; 3 ; 4 ; 5$; $6.3 ; 8 ; 10 ; 12.5 \mathrm{~mm}$. The final product, after performing the sieve analysis, was subjected to strength tests.

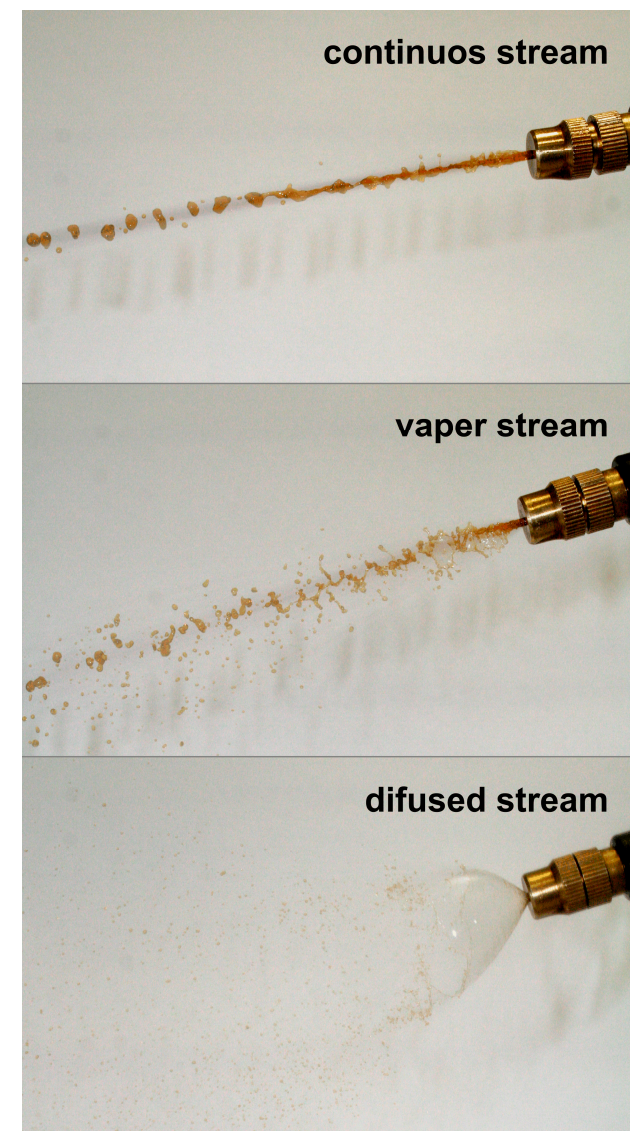

Figure 2. Types of streams used to supply the binder (moisturizing liquid).

A two-stage granulation study was carried out using a high-speed mixer and a disc granulator (Figure 3).

\section{Mixer granulation}
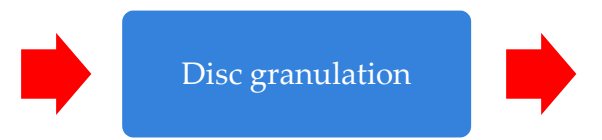

Figure 3. Two-stage granulation scheme.

It was assumed that the processed mixture of sulfogypsum and limestone powder would be pre-granulated in an Eirich mixer, which would ensure nucleation of the raw material grains, and then "granulated" in a disc granulator. The operation carried out in the mixer was aimed at greater compaction of the embryos formed (obtained as a result of high inertia forces), while the disc granulation stage led to the appropriate particle size composition and strength. Chronologically, the first step of this method was the mixer granulation. The mixer agglomeration stage was carried out in the Eirich granulator, which we can see in Figure 4. The figure shows a rotating bowl constituting the working chamber of the granulator and the cover to which the stirrer is attached. 


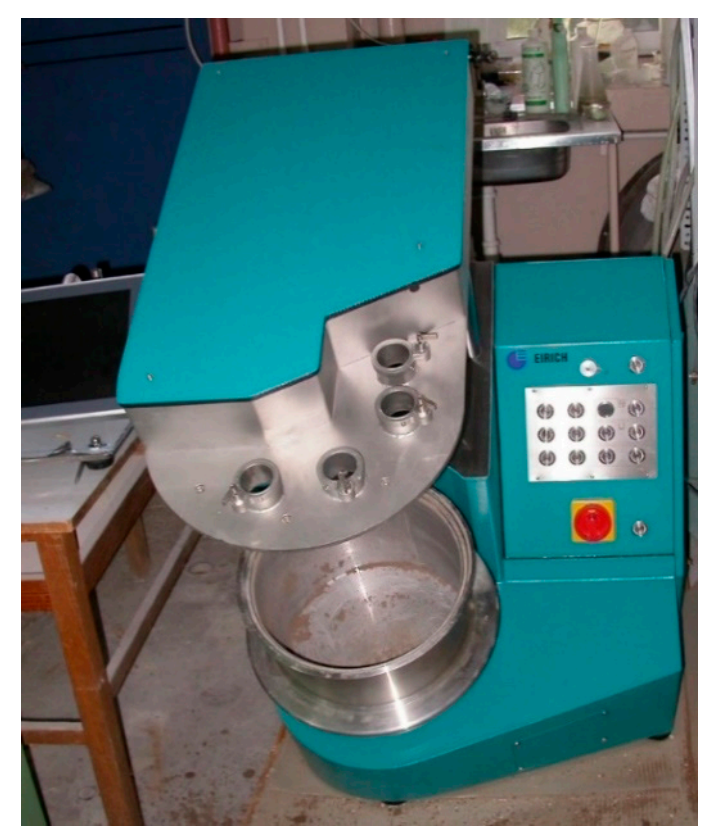

Figure 4. Granule mixer by Maschinenfabrik Gustav Eirich GmbH and Co KG (Germany).

A mixture of $1000 \mathrm{~g}$ of lime flour and $1000 \mathrm{~g}$ of sulfogypsum was supplied to the high-speed granulator. After the granulator cover was closed, the stirrer and the bowl were put in rotation, with the directions of rotation being consistent. The circumferential speed of the bowl and the stirrer were, respectively, 0.7 and $2.4 \mathrm{~m} \cdot \mathrm{s}^{-1}$.

While the bowl and agitator were rotating, a 20\% aqueous solution of magnesium lignosulfonate was fed to the blend and the process continued for a predetermined time. After the mixing time had elapsed, the moistened and pre-granulated material was placed in the disc granulator. After a predetermined time of agglomeration without wetting carried out in the disc granulator, the apparatus was stopped, the bed obtained was dried and the material was screened for particle size analysis, and then the strength of individual fractions was tested. In order to determine the ability of granulated fertilizer to apply calcium and sulfur compounds to the soil, the time of granule disintegration in a humid environment was examined. The disintegration time of the granules was measured during a test in which the granules obtained were mixed in water. The parameters of Mixer granulation: mass of solution and time of granulation were placed in Table 2. Two hundred milliliters of water was poured into the vessel and $100 \mathrm{~g}$ of granules with a fraction size of 1-8 mm were added. The mixture thus formed was mixed at a stirrer speed of $20 \mathrm{rpm}$. The rotational speed was selected so that the agitator did not destroy the granules while rotating. The time after which all the granules had disintegrated as a result of the binder dissolution was determined. In order to determine the strength properties of the granulate obtained, compressive strength tests were carried out, in which the compressive force causing destruction of the granules was determined. The results obtained for trials 1-6 are presented in Table 3 and for trials 7-10 in Table 4.

Table 2. The parameters of Mixer granulation.

\begin{tabular}{cccc}
\hline & Mass of the Solution & \multicolumn{2}{c}{ Time of Granulation } \\
\cline { 2 - 4 } Sample No. & g & Mixer & Disc \\
\cline { 2 - 4 } & 200 & & s \\
I & 170 & 180 & 60 \\
II & 70 & 60 & 60 \\
III & 60 & 60 \\
\hline
\end{tabular}


Table 3. Strength test results, test 1-6.

\begin{tabular}{|c|c|c|c|c|c|c|}
\hline \multicolumn{7}{|c|}{ Comparison of Granulate Strength } \\
\hline \multirow{2}{*}{ Sample No. } & \multirow{2}{*}{ Fraction, mm } & \multicolumn{4}{|c|}{ Destructive Force, $\mathbf{N}$} & \multirow[t]{2}{*}{ Final Humidity, $\%$} \\
\hline & & Min & Max & Average & Absolute Mean Error & \\
\hline \multirow{6}{*}{1} & 2 & 1.03 & 8.3 & 3.2 & 3.2 & \multirow{6}{*}{15.9} \\
\hline & 3 & 4.7 & 7.9 & 6 & 2.1 & \\
\hline & 4 & 4.2 & 9.2 & 7.7 & 2.8 & \\
\hline & 5 & 9.6 & 20.6 & 12.2 & 3.2 & \\
\hline & 6.3 & 6.6 & 26.6 & 15.4 & 3.9 & \\
\hline & 8 & 17.5 & 29.3 & 20.8 & 4.1 & \\
\hline \multirow{6}{*}{2} & 2 & 5.7 & 16.9 & 10.2 & 3.1 & \multirow{6}{*}{21.7} \\
\hline & 3 & 4.8 & 20.9 & 12.6 & 4.8 & \\
\hline & 4 & 15.7 & 31.9 & 21.3 & 5.1 & \\
\hline & 5 & 21.9 & 49.9 & 37 & 8.9 & \\
\hline & 6.3 & 24 & 92 & 53 & 14.1 & \\
\hline & 8 & 27.5 & 87.5 & 48.5 & 13.4 & \\
\hline \multirow{6}{*}{3} & 2 & 2.5 & 14 & 6.9 & 1.9 & \multirow{6}{*}{19.5} \\
\hline & 3 & 7 & 12 & 9.6 & 2.4 & \\
\hline & 4 & 12.1 & 44.6 & 19.8 & 4.9 & \\
\hline & 5 & 17 & 23.2 & 20.4 & 2.1 & \\
\hline & 6.3 & 24.8 & 43.3 & 33.4 & 5.6 & \\
\hline & 8 & 22.4 & 49.4 & 34.8 & 6.6 & \\
\hline \multirow{6}{*}{5} & 2 & 0.8 & 2.4 & 1.8 & 0.7 & \multirow{6}{*}{15.9} \\
\hline & 3 & 2.4 & 5.9 & 3.3 & 1 & \\
\hline & 4 & 1.5 & 5.3 & 3.1 & 1.4 & \\
\hline & 5 & 2.7 & 5.1 & 3.6 & 1.3 & \\
\hline & 6.3 & 6.9 & 8.9 & 7.3 & 2.1 & \\
\hline & 8 & 3.3 & 9.8 & 9.6 & 3.1 & \\
\hline \multirow{6}{*}{6} & 2 & 7 & 64.1 & 29.7 & 8.2 & \multirow{6}{*}{22.7} \\
\hline & 3 & 9.1 & 19.6 & 15.8 & 4.2 & \\
\hline & 4 & 21.1 & 35 & 24.7 & 3.8 & \\
\hline & 5 & 17 & 43.2 & 24.3 & 7.3 & \\
\hline & 6.3 & 32 & 87.2 & 58 & 14.2 & \\
\hline & 8 & 33.9 & 64.9 & 54.1 & 12.6 & \\
\hline
\end{tabular}

The work also compares the results of one-stage disc granulation with the use of $20 \%$ magnesium lignosulfonate solution with analogous granulation tests with the use of $20 \%$ molasses waste solution. The granular material was, in both cases, a mixture of waste gypsum and lime flour. The results of granulation presented with the use of molasses were obtained from the research, the results of which were published in the article. In the relationships presented in Figure 10, the tests with the use of molasses are marked with the letter $\mathrm{M}$, and the tests in which the bed was moistened with magnesium lignosulfonate with the letter $\mathrm{L}$. The same granulation time was adopted for all the tests compared-12 min. The masses of the added $20 \% \mathrm{mr}$ wetting solutions were 70 and $80 \mathrm{~g}$ per $1000 \mathrm{~g}$ of gypsum-lime mixture.

After pre-mixing, the binding liquid was dispensed. The mixer granulation time was $180 \mathrm{~s}$. Two hundred grams of the solution was added to the bed (test I). After completion of the mixer granulation, the material was granulated in a disk granulator. After the disc granulation, the material was placed in an oven and dried for $90 \mathrm{~min}$ at $100{ }^{\circ} \mathrm{C}$. The granulate obtained was subjected to sieve analysis and then its strength was tested. The results are presented in Tables 3 and 4. 
Table 4. Strength test results, tests 7-10.

\begin{tabular}{|c|c|c|c|c|c|}
\hline \multirow{3}{*}{ Sample No. } & \multicolumn{4}{|c|}{ Comparison of Granulate Strength } & \multirow{3}{*}{ Final Humidity, $\%$} \\
\hline & \multirow{2}{*}{ Fraction, $\mathrm{mm}$} & \multicolumn{3}{|c|}{ Force, $\mathbf{N}$} & \\
\hline & & Min & $\operatorname{Max}$ & Average & \\
\hline \multirow{6}{*}{7} & 2 & 1.1 & 3.6 & 1.9 & \multirow{6}{*}{17.6} \\
\hline & 3 & 2.7 & 5.5 & 3.9 & \\
\hline & 4 & 1.4 & 6.2 & 3.4 & \\
\hline & 5 & 6 & 23 & 15 & \\
\hline & 6.3 & 10 & 25 & 20 & \\
\hline & 8 & 13.3 & 25.3 & 17.1 & \\
\hline \multirow{6}{*}{8} & 2 & 1.1 & 2.4 & 2 & \multirow{6}{*}{16.7} \\
\hline & 3 & 1 & 4.1 & 2.7 & \\
\hline & 4 & 3.3 & 8.4 & 5 & \\
\hline & 5 & 6.2 & 8.1 & 7.1 & \\
\hline & 6.3 & 9.7 & 23.7 & 15.5 & \\
\hline & 8 & 4 & 26 & 14.8 & \\
\hline & 2 & 3.4 & 4.8 & 3.9 & \multirow{6}{*}{19.3} \\
\hline & 3 & 2.3 & 6.8 & 5.6 & \\
\hline & 4 & 8.8 & 14.1 & 11 & \\
\hline 9 & 5 & 18.3 & 29.3 & 26.5 & \\
\hline & 6.3 & 28.4 & 42.4 & 36 & \\
\hline & 8 & 7 & 67.6 & 38.7 & \\
\hline \multirow{6}{*}{10} & 2 & 8.2 & 28.2 & 14.2 & \multirow{6}{*}{20.6} \\
\hline & 3 & 7.6 & 18.2 & 10.7 & \\
\hline & 4 & 10.1 & 26.1 & 20.1 & \\
\hline & 5 & 8.1 & 47.1 & 29.1 & \\
\hline & 6.3 & 40.1 & 52.1 & 44.5 & \\
\hline & 8 & 34.8 & 78.8 & 51 & \\
\hline
\end{tabular}

Due to the high content of the binding liquid, the granulate was characterized by good strength parameters. Unfortunately, such an amount of added binder made the material too wet after the mixer granulation step, which caused it to stick together (coalescence) during the disc granulation (Figure 13). Thus, high material humidity disturbed the granulation process by the encapsulation method. The longer the plate process was carried out, the larger and more misshapen the granules formed. In further tests, it was decided to reduce the weight of the added binder. Test II was also carried out with the use of $1000 \mathrm{~g}$ of limestone powder and $1000 \mathrm{~g}$ of waste gypsum. A $20 \%$ solution of magnesium ligninsulfonate was reused. The rotation of the bowl and the stirrer were unchanged. The bowl of the mixer granulator was filled with the raw mix, then the apparatus was started, and the material was mixed for $60 \mathrm{~s}$. Over the next $60 \mathrm{~s}, 170 \mathrm{~g}$ of the solution was added to the bed. The pre-granulated and moistened bed was transferred to a disc granulator and the granulation process continued. The product obtained was dried for $90 \mathrm{~min}$ at 100 ${ }^{\circ} \mathrm{C}$. Then, the dried granules were subjected to sieve analysis and strength tests. The test results obtained are presented in Tables 5 and 6.

Table 5. Results of the sieve analysis, test I-III.

\begin{tabular}{ccccc}
\hline \multicolumn{5}{c}{ Sieve Analysis } \\
\hline Test No. & Oversize & $\mathbf{4 - 8} \mathbf{~ m m}$ & $\mathbf{1 - 4} \mathbf{~ m m}$ & Undersize \\
\hline- & $\%$ & $\%$ & $\%$ & $\%$ \\
\hline I & 26.3 & 41.2 & 30.8 & 1.7 \\
II & 2.6 & 48 & 48.4 & 1 \\
III & 4.4 & 49.2 & 38 & 8.4 \\
\hline
\end{tabular}


Table 6. Strength test results, test I-III.

\begin{tabular}{|c|c|c|c|c|c|c|}
\hline \multicolumn{7}{|c|}{ Comparison of Granulate Strength } \\
\hline \multirow{2}{*}{ Test No. } & \multirow{2}{*}{ Fraction, $\mathrm{mm}$} & \multicolumn{4}{|c|}{$\begin{array}{l}\text { Force, } \mathbf{N} \\
\end{array}$} & \multirow{2}{*}{ Final Humidity, $\%$} \\
\hline & & Min & $\operatorname{Max}$ & Average & Absolute Mean Error & \\
\hline \multirow{2}{*}{ I } & $1.0-4.0$ & 18.5 & 72 & 36 & 12 & 8.5 \\
\hline & $4.0-8.0$ & 36.4 & 112.4 & 72.2 & 9.58 & 8.9 \\
\hline \multirow{2}{*}{ II } & $1.0-4.0$ & 12.8 & 50.5 & 32.3 & 7.54 & \multirow{2}{*}{9.1} \\
\hline & $4.0-8.0$ & 20.8 & 90.6 & 53.2 & 12.5 & \\
\hline \multirow{2}{*}{ III } & $1.0-4.0$ & 2.1 & 17.7 & 11.3 & 2.63 & 2 \\
\hline & $4.0-8.0$ & 8 & 36.3 & 19.5 & 3.73 & 5.6 \\
\hline
\end{tabular}

\subsection{Testing the Compressive Strength of Granules and Their Disintegration}

The compressive strength of granules was tested using an Instron 3345 device. The analyzer was manufactured by Instron, part of Illinois Tool Works. The material to be tested was placed between the squeezing jaws. The device registered the increase of the compressive force along with the movement of the moving jaw (Figure 5). The value of the pellet destructive force was considered to be the value equal to the extreme in the diagram of changes of the compressive force due to the displacement of the compression jaw of the apparatus. Ten granules from the size fraction were tested, and the results obtained were used to determine the minimum, maximum, and arithmetic mean force causing damage.

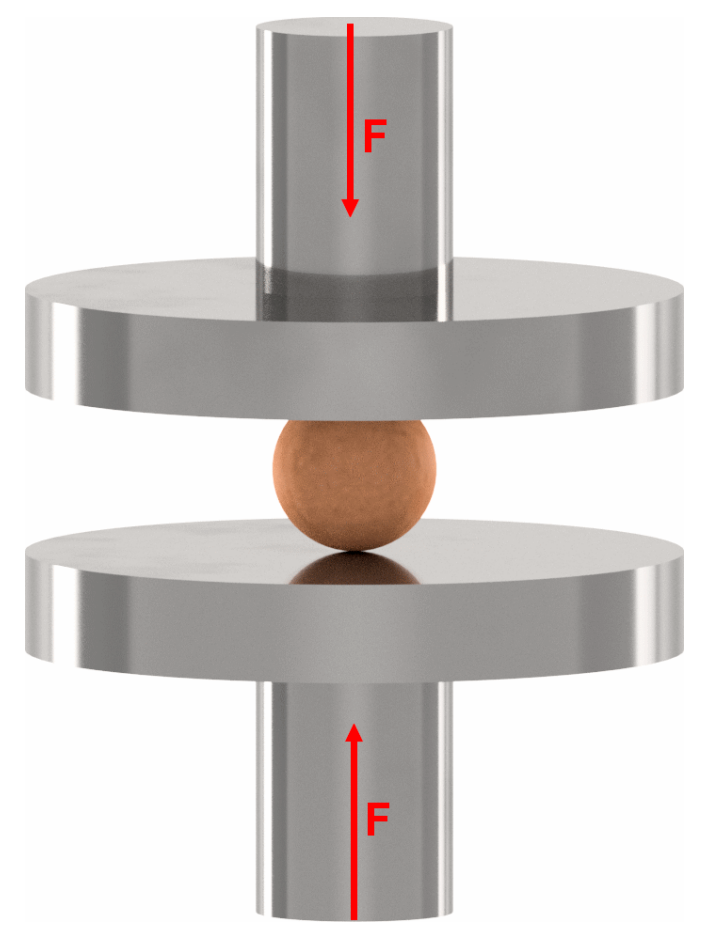

Figure 5. Scheme of loading fertilizer granules with compressive forces $\mathrm{F}$.

Tests are named according to the procedure below:

- tests 1-10 concerned the examination of granulated material in samples 1-10 (Table 1)

- $\quad$ tests I-III concerned the examination of granulated material in tests I-III (Table 2)

\section{Research Results}

The study compares the results obtained during the one-stage disc and two-stage granulation. In both processes, a mixture of waste gypsum and lime flour was granulated. 
The binding liquid comprised $20 \%$ solutions of magnesium lignosulfonate and molasses. In the course of the analysis, the granulation time, the weight of the moisturizing liquid, and the type of spray were adopted as comparative criteria.

\subsection{One-Step Granulation 1}

An example of a comparison of the results of single-stage disc granulation tests for different moistening times is presented in Figure 6. This resulted in the supply of different masses of lignosulfonate solution to the lime-gypsum mixture. The test was carried out while moistening the bed with a continuous stream. The bed was moistened with a hydraulic nozzle. The graphs compare the percentages obtained by mass of individual fractions, i.e., the mass of individual fractions relative to the total mass of the granulate obtained.

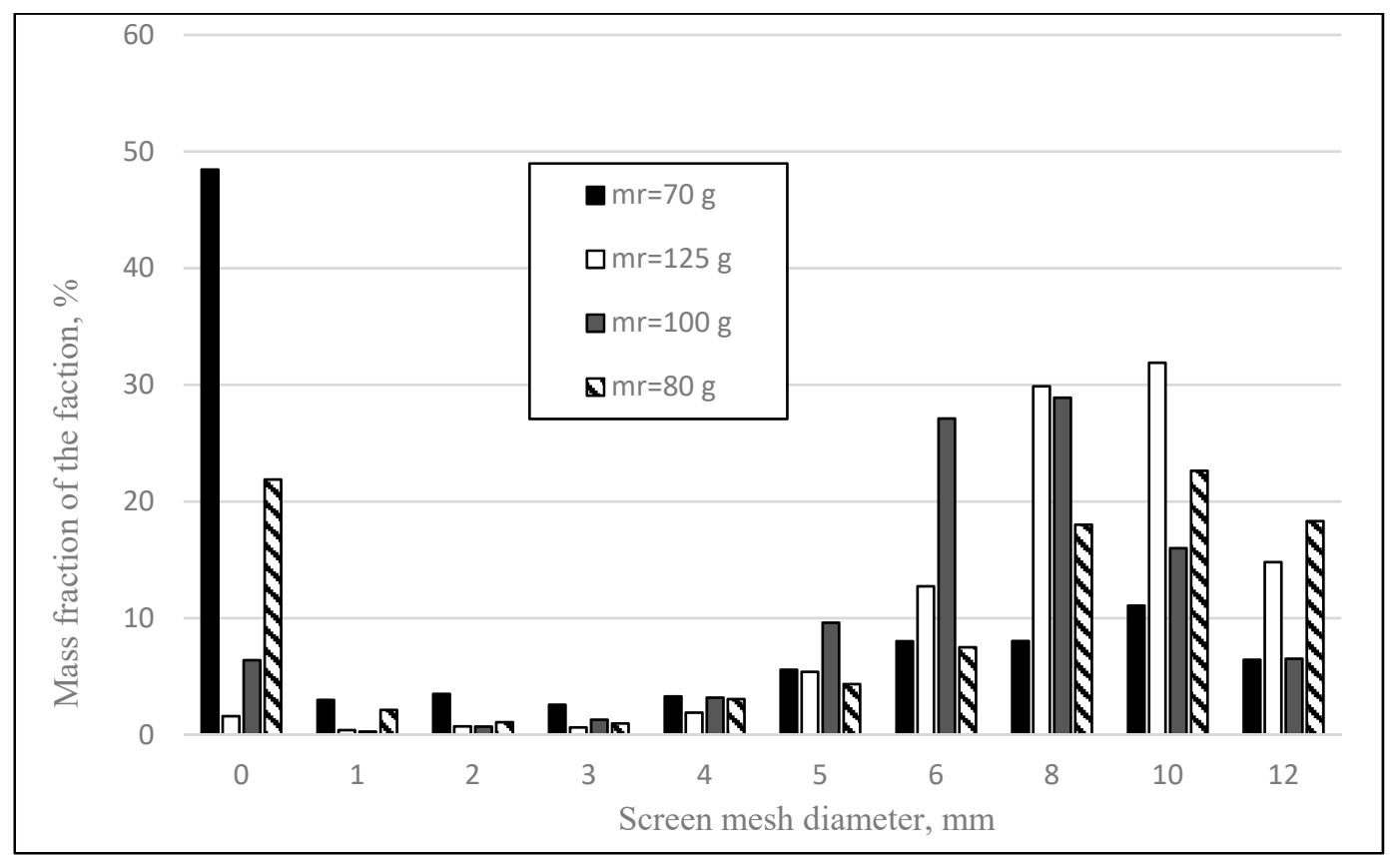

Figure 6. Comparison of the mass fractions (percentages) of the granulate obtained for different amounts of the added solution (liquid dosing by means of a continuous stream), (mr-mass of the solution).

In order to determine the strength properties of the granulate obtained, compressive strength tests were carried out, in which the compressive force causing destruction of the granules was determined. The results obtained for trials 1-6 are presented in Table 3.

The graphical relationships obtained show that with a small amount of moisturizing liquid (70 g per $1000 \mathrm{~g}$ of feed), the mixture of raw materials was not completely granulated. For the tests in which $70 \mathrm{~g}$ and $80 \mathrm{~g}$ of lignosulfonate solution were used, after the end of the process, a significant share of the $0-1 \mathrm{~mm}$ fraction ( $48 \%$ for $70 \mathrm{~g}$ and $23 \%$ for $80 \mathrm{~g}$ ) was visible, which was considered non-granular. When 100 or $125 \mathrm{~g}$ of the solution is delivered to the bed, it can be seen that ungranulated or abraded material (0-1 mm fraction) is only $1 \%$ for $125 \mathrm{~g}$ and $6 \%$ for $100 \mathrm{~g}$ of solution. The experiment in which $100 \mathrm{~g}$ of lignosulfonate solution was injected into the bed was considered as the test in which the most favorable particle size distribution of the product was obtained. It is characterized by a low mass of non-granulated material and over $73 \%$ share of 1-10 mm fractions. By dosing the binder with a continuous stream, it is very easy to obtain local moistening of the raw material. This results in the possibility of wet material sticking together and a high probability of the formation of granules with an equivalent diameter above $10 \mathrm{~mm}$, which are oversized in the production of fertilizer. This happens all the more when the continuous stream of liquid collides directly with the material being processed. In order to counteract such a 
phenomenon, the liquid should be supplied from an appropriate height and pressure that will break the continuous stream (the stream may break just above the bed) into drops with an equivalent diameter of approximately $2-3 \mathrm{~mm}[48,49]$.

The work includes tests in which a different method of liquid delivery was also proposed, with the help of fog and a dispersed stream. The experiments carried out have shown that the delivery of the binding liquid through a mist-generating nozzle requires careful dosing. The dispersed droplets settle on the walls, bottom of the disc, and the scraper and disturb the process of granulate formation. Moreover, even moistening of a large surface of the bed flowing in the plate results in the fact that we do not obtain sufficient humidity in the discussed area to initiate the nucleation process of granules, despite the fact that a lot of liquid was supplied to the bed. The mass of the supplied liquid then penetrates evenly between the grains of the entire mass of the raw material. Although the average humidity of the bed is relatively high, for a long time sufficiently high local humidity is not obtained (as in the case of humidification with a stream) so as to allow nucleation and subsequent granulation.

The results of the tests carried out when dispensing liquids with a nozzle producing a micro-droplet vapor in Figure 7 show that when $70 \mathrm{~g}$ of solution was used, the fraction of $0-1 \mathrm{~mm}$ constituted over $60 \%$ of the mass fraction. This proves that the mass of the liquid supplied is too low, which inhibited the process. The comparison of both methods of moistening showed that in the experiment, in which a continuous stream was used for the same mass of solution $(70 \mathrm{~g})$, the proportion of non-granulated material after the end of the process was lower by $13.5 \%$. This shows that the punctual delivery of the liquid allowed nucleation, unlike a method where the liquid was delivered evenly.

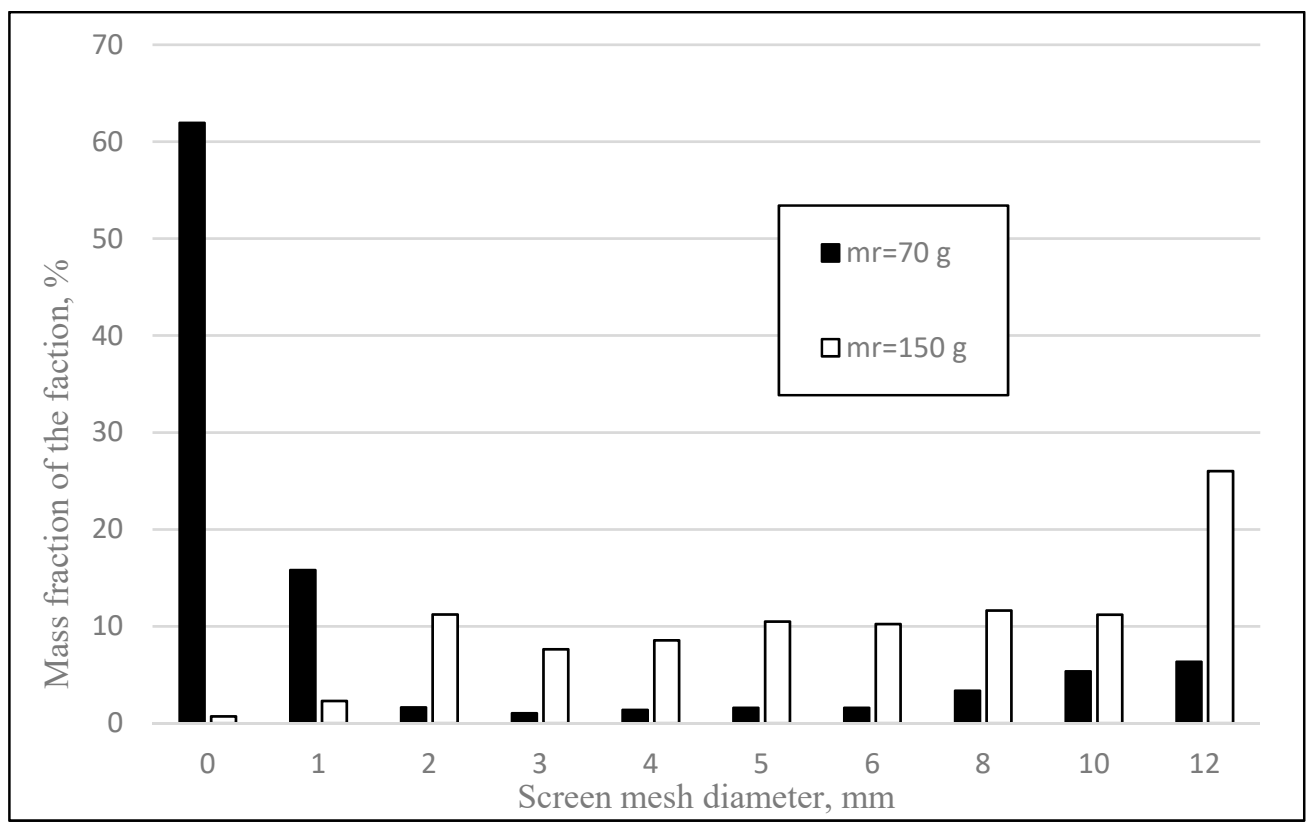

Figure 7. Comparison of the mass fractions of the granulate obtained for tests in which the liquid was dosed with vapor (mr-mass of the solution).

After increasing the mass of the moisturizing liquid to $150 \mathrm{~g}$ (trial 6), a 99\% granulated product was obtained, with even mass distribution. This granulate was characterized by high resistance to compressive force (Table 3), which was the result of using a large mass of the binding liquid. However, the addition of a large mass of liquid caused the granules to be moistened and their size increased rapidly (Figure 8). 


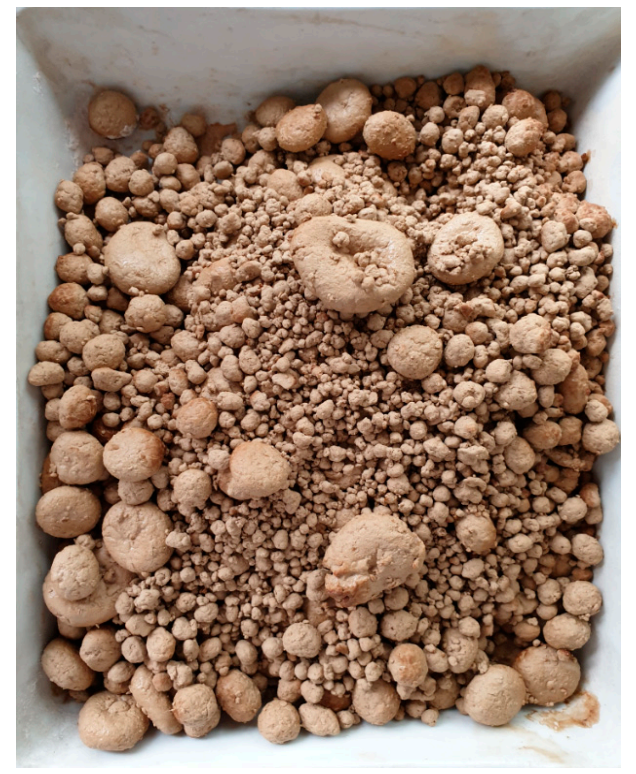

Figure 8. Granules obtained after feeding $150 \mathrm{~g}$ of a solution in the form of a "vapor" to the bed (trial 6).

The disadvantage of the granulate obtained was its very irregular shape (Figure 9), which resulted from the phenomenon of coalescence, i.e., the sticking together of smaller agglomerates. This phenomenon especially concerned granules larger than $10 \mathrm{~mm}$. This is disadvantageous, weakening the strength of the product (the product breaks along the line of connecting the granules into a larger agglomerate), and also has a negative impact on appearance, and thus on commercial properties. The disadvantage of such selected parameters also included the high final humidity of the product, which resulted in higher costs of drying the product.

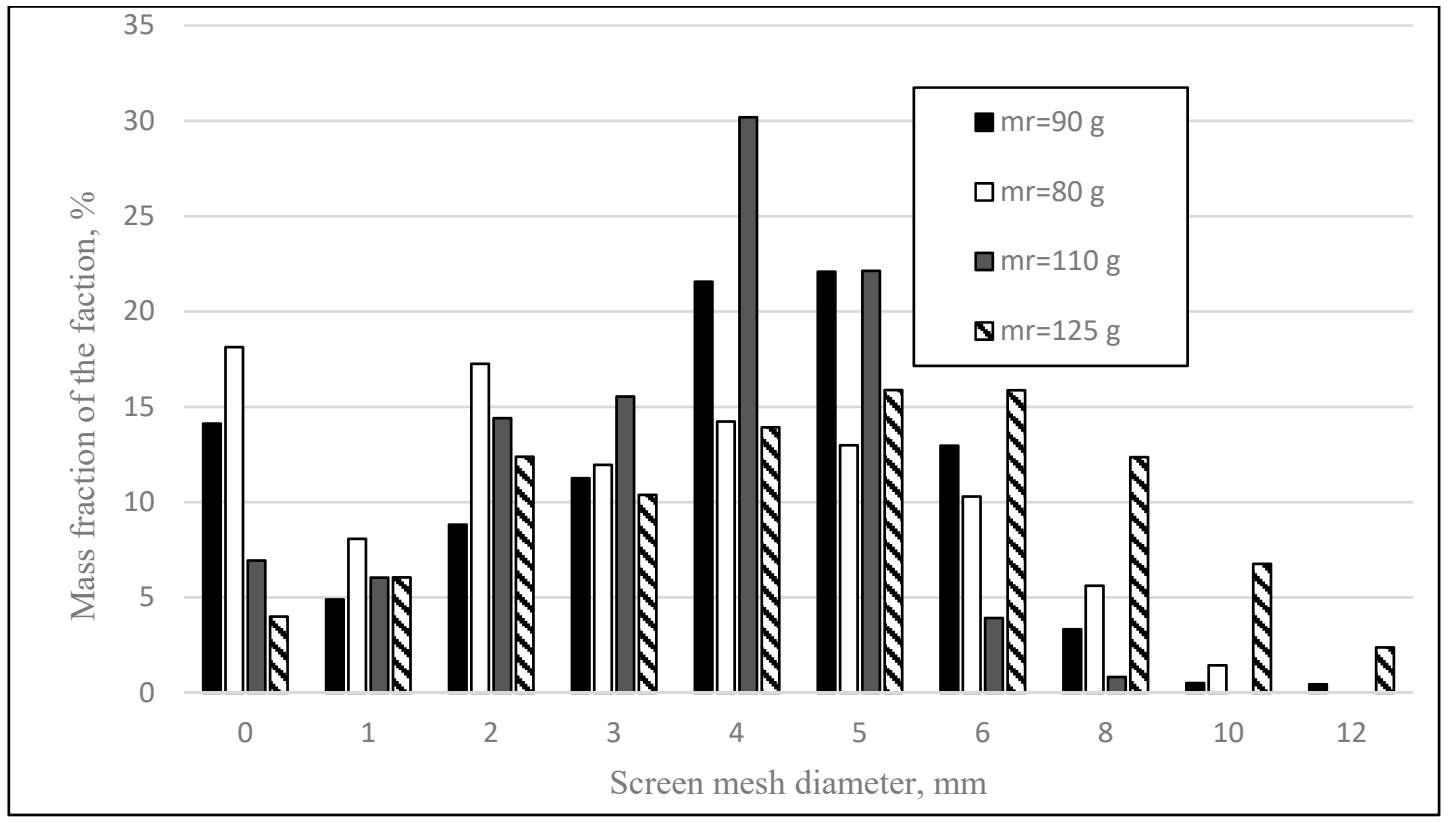

Figure 9. Comparison of the mass fractions of the granulate obtained in the tests with the dosing of the added solution by means of a dispersed stream (mr-mass of the solution).

In subsequent tests (7-10), a dispersed stream was used to moisturize the mixture. This is an intermediate stream between the continuous stream and the fog, i.e., the one 
whose drops most often have diameters of $0.25-2 \mathrm{~mm}$. In tests 9 and 10 , in which $110 \mathrm{~g}$ or $125 \mathrm{~g}$ of the solution were added to $1000 \mathrm{~g}$ of raw material, over $80 \%$ of the desired fraction was obtained (see Figure 7). Moreover, the granulate in both tests was characterized by high compressive strength (Table 4). Adding $90 \mathrm{~g}$ of the solution to the gypsum-lime mixture in test 7 also obtained a fraction of over $80 \%$ of the $1-10 \mathrm{~mm}$ fraction, but the granulate obtained in such moistening was more brittle and was damaged more easily.

Delivering $80 \mathrm{~g}$ of the solution in test 8 means that $26 \%$ of the granulate obtained is sub-grain $(d<1 \mathrm{~mm})$. The comparison of the mass fractions of the granules obtained in the tests with the dosing of the added solution by means of a dispersed stream is shown in Figure 9. This proves the role of the mass of the liquid supplied to the bed. It is clearly visible that test 7 , in which only $80 \mathrm{~g}$ of the solution was added, is characterized by a large subgrain weight, while trial 10 , although it has a satisfactory composition, yields about $10 \%$ oversize, which then needs to be crushed for further processing. The weight of the water supplied is important here, which determines the moisture of the bed (which favors granulation) and the weight of the binder (in this case, lignosulfonate), which in turn affects the strength of the obtained product. The results lead to the conclusion that the optimal mass of the added liquid is that in which we obtain a bed with a small amount of oversize and undersize, characterized by adequate strength. These conditions are met by test 9 $(\mathrm{mr}=110 \mathrm{~g})$. Pictures of the granulate obtained in tests 9 and 10, in which the granules of individual fractions were compared, are shown in Figure 10.

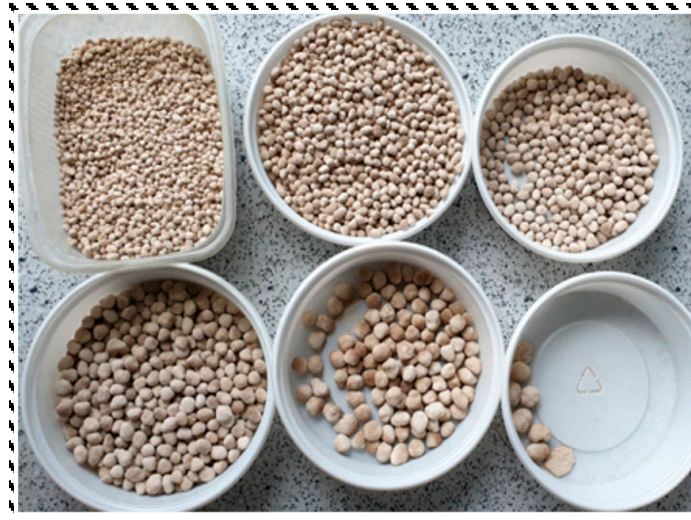

(a)

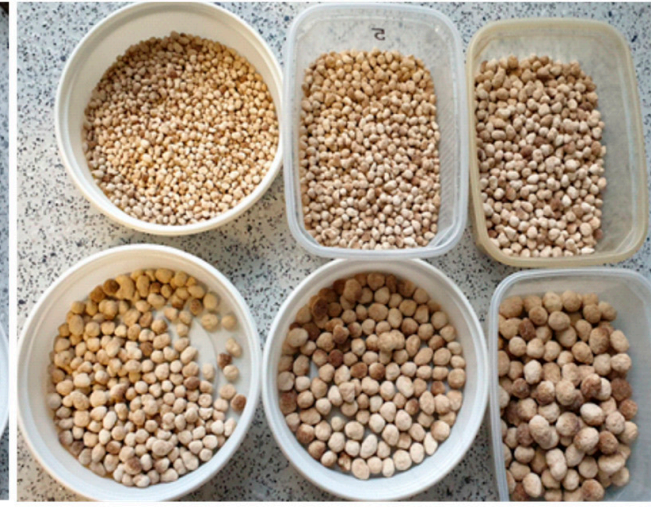

(b)

Figure 10. Granulate obtained in tests 9 (a) and tests $10(\mathbf{b})$.

Figure 11 presents a comparison of the granulation effects of the gypsum-lime mix as a function of the type of moisturizing stream used. In both results of the tests presented graphically, the granulation time was $6 \mathrm{~min}$ and $125 \mathrm{~g}$ of a $20 \%$ solution of magnesium lignosulfonate was used. The dependencies presented confirm that the liquid dosing method, and therefore the droplet size, has a great influence on the particle size distribution of the product obtained. Using a continuous stream, it is easier to obtain granules with larger diameters. The use of a dispersed stream allows granules to be obtained with smaller equivalent diameters and a more uniform particle size distribution.

The analysis of the results presented in Figure 12 shows that granulation with moistening of the gypsum-lime mixture with molasses allows more favorable particle size compositions of the obtained products to be obtained than tests with the use of lignosulfonate. During granulation, which differed only in the moisturizing liquid used, a product was obtained in which there were almost no granules above $10 \mathrm{~mm}$, and the sub-grain size was from $4 \%$ to $9 \%$. The research conducted has shown that in the case of moistening with $20 \%$ magnesium lignosulfonate solution, in order to obtain a favorable particle size distribution, the granulation time should be extended. The comparison of granulation tests with the use of both liquids for different granulation times (tests with molasses $12 \mathrm{~min}$, tests with lignosulfonate $6 \mathrm{~min}$ ) is shown in Figure 13. 


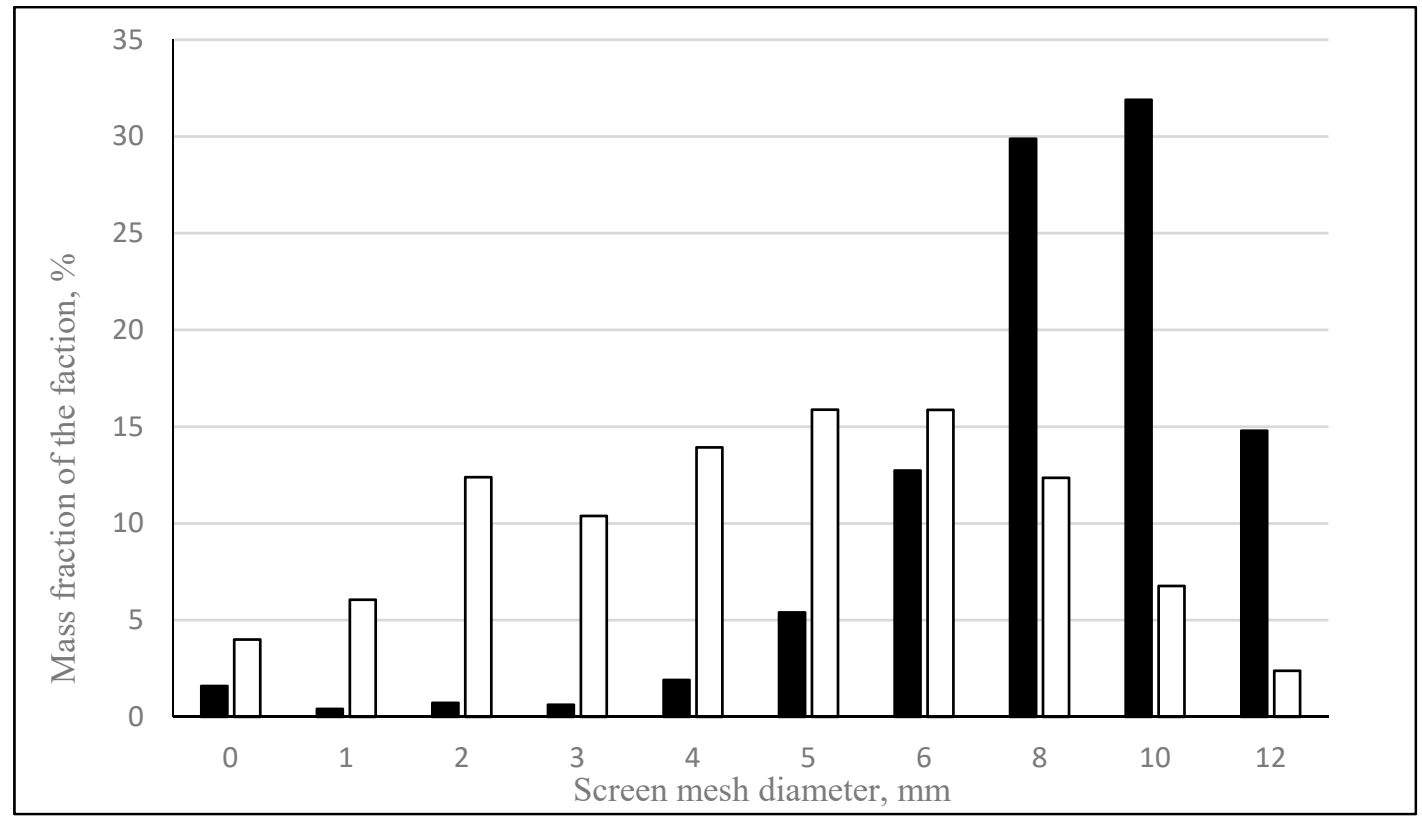

Figure 11. Comparison of the mass fractions of the granulate obtained in tests carried out with liquid dosing by means of a continuous (black color) and dispersed stream (white color).

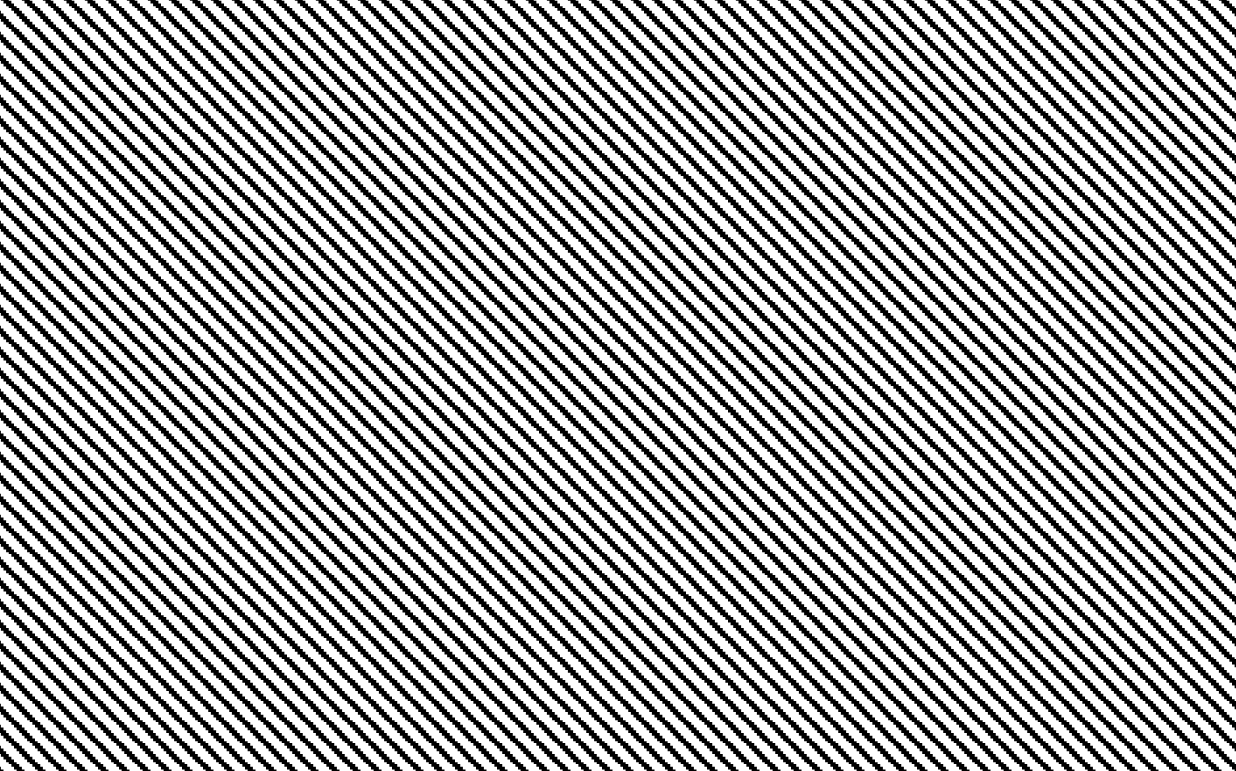

Figure 12. Comparison of the mass fractions of the granulate obtained for tests carried out during moistening with molasses (M) and magnesium lignosulfonate (L) (granulation time, $\operatorname{tg}=12 \mathrm{~min}$ ), (mr-mass of the solution).

As a result of adding more liquid mass and reducing the granulation time by $6 \mathrm{~min}$, satisfactory particle size compositions were obtained, comparable to the results obtained when moistening with molasses. The granules obtained had a smaller diameter, which should be considered favorable. Unfortunately, this was associated with the appearance of undersize (14-19\%).

Regardless of the liquid used, for 80 and $90 \mathrm{~g}$ of the added binder, the granulometric composition of the product was practically free of oversize. Such granulation effect with the use of lignosulfonate was found to be satisfactory and in line with the manufacturer's expectations. It was found that during granulation on an industrial scale, the sub-grain size of a dozen or so percent without additional operations and the related costs can be returned to repeated granulation. Summarizing the results of one-step granulation, it was 
decided in Figure 14 to compare the results of the tests considered the most successful for both liquids used. The most successful tests were those in which the largest amount of agglomerate was obtained from the $2-8 \mathrm{~mm}$ fraction with simultaneous high resistance of the granules formed to strength tests.

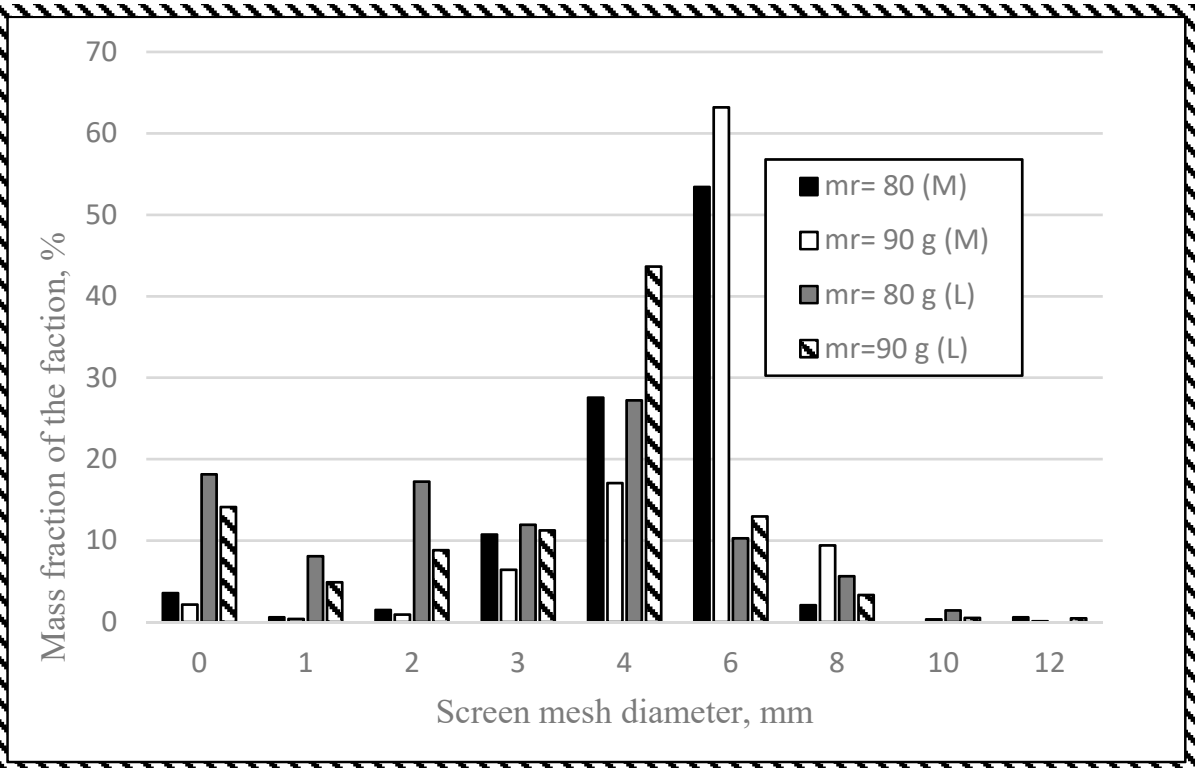

Figure 13. Comparison of the mass fractions of the granulate obtained for different granulation times-tests with molasses (M), $\operatorname{tg}=12 \mathrm{~min}$ and tests with lignosulfonate (L), $\operatorname{tg}=6 \mathrm{~min}$, (mr-mass of the solution).

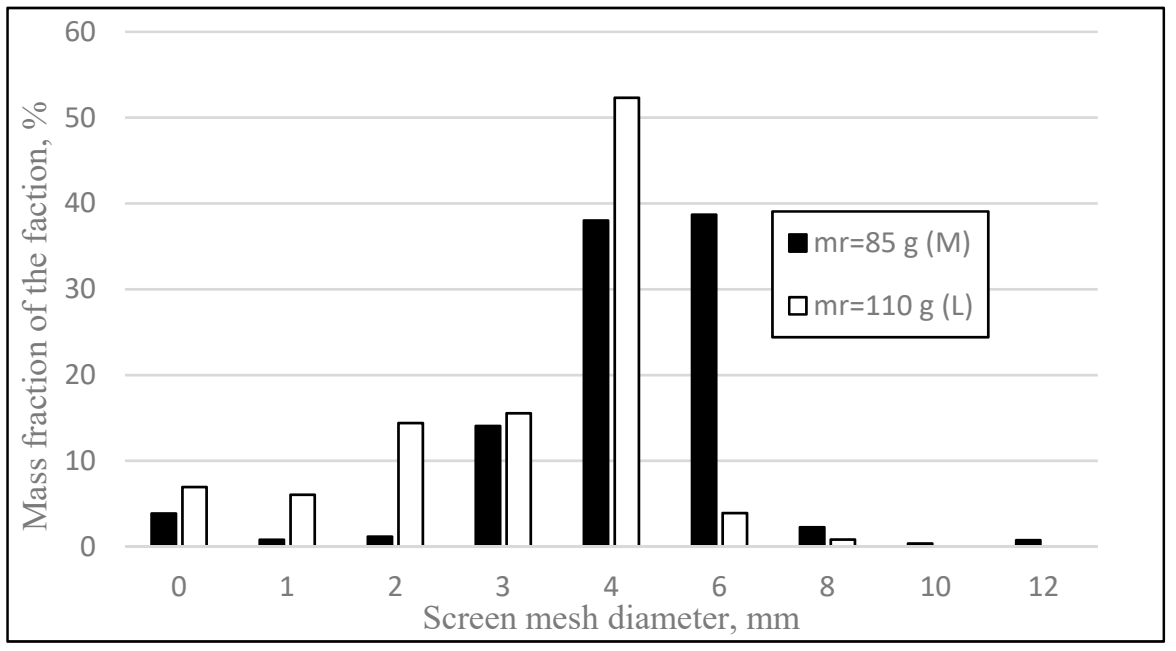

Figure 14. Comparison of the mass shares for the most successful trials. (M)-moistening with an aqueous solution of molasses, (L)-moistening with an aqueous solution of lignosulfonate, (mr-mass of the solution).

The results presented in Figure 14 confirm the conclusion that for the one-step granulation of agricultural fertilizers, composed of a mixture of limestone and sulfogypsum, water solutions of molasses and magnesium lignosulfonate can be used interchangeably. Granulation with the use of molasses permitted a $92 \%$ fraction of $2-8 \mathrm{~mm}$ to be obtained, and granulation with lignosulfonate $84 \%$. The disadvantage of the one-step method was the high humidity of the product obtained, which resulted from the initial humidity of the sulfogypsum (it was considered ineffective to dry the raw material and to moisten it later) and the mass of the supplied liquid. 


\subsection{Two-Step Granulation}

In order to eliminate the disadvantages of one-step granulation, it was decided to carry out two-step granulation trials. One thousand grams of limestone powder and $1000 \mathrm{~g}$ of waste gypsum were used to carry out the two-stage granulation tests. A $20 \%$ magnesium lignosulfonate solution was used as the binder liquid. The bowls and the stirrer rotated at a peripheral speed of $0.7 \mathrm{~m} / \mathrm{s}$ and $2.4 \mathrm{~m} / \mathrm{s}$, respectively. The ingredients were added into the bowl of the mixer granulator and then mixed for $60 \mathrm{~s}$ to equalize the compositions.

The granulometric analysis shows that the total percentage by weight of the most favorable fraction (1-8 $\mathrm{mm}$ ) was $96.4 \%$. Reducing the amount of binder by $30 \mathrm{~g}$, compared to test I, also allowed the reduction of the oversize fraction by $23.7 \%$ to the level of $2.6 \%$. A product with satisfactory strength results as well as a satisfactory appearance was obtained. The humidity of the granulate mass was adequate, the surface of the agglomerates after the first stage of the process was dry enough to allow efficient disc granulation. It shows wet granules, which could, in the future, hinder and irritate the drying process and cause additional, this time unfavorable agglomeration in its duration. In trial III, analogous parameters of the two-stage granulation were used as in the previous trials, with the only difference being the dosing of $70 \mathrm{~g}$ of lignosulfonate solution. After completion of both granulation stages, the material was dry on the surface (Figure 15), which was placed in an oven and dried for $90 \mathrm{~min}$ at $100^{\circ} \mathrm{C}$. The granulate obtained was subjected to sieve analysis and then its strength was tested. The results are shown in Tables 5 and 6 . The photo in Figure 16 shows the granulate obtained after the second stage of two-stage granulation, i.e., after disc granulation.

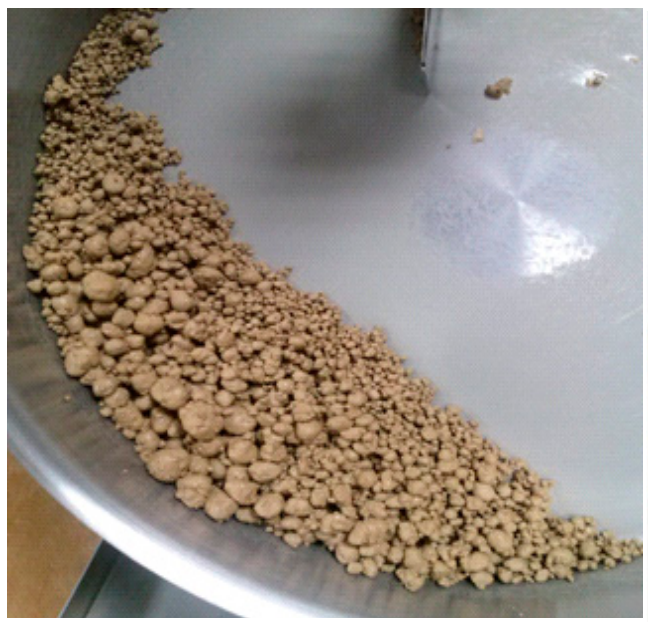

Trial I

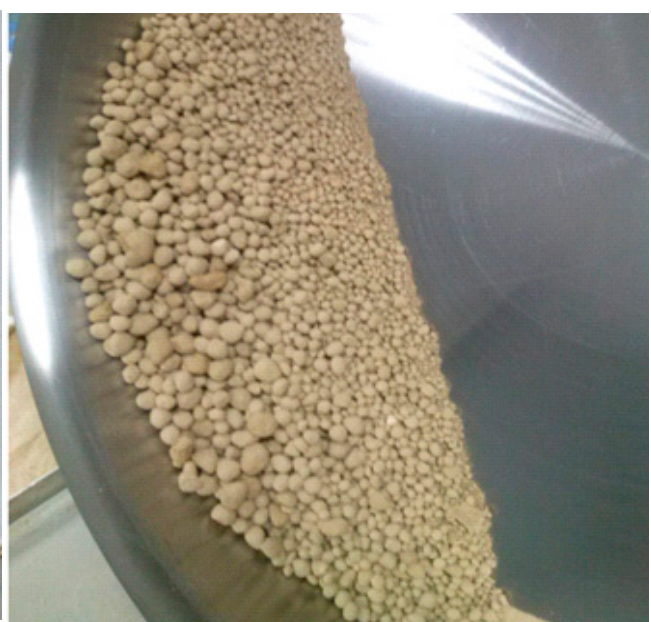

Trial III

Figure 15. Dampened granules (tests I and III) on a plate prior to disc granulation.

The results of the sieve analysis show that the two-step granulation carried out with dosing $70 \mathrm{~g}$ of lignosulfonate solution per $2000 \mathrm{~g}$ of the blend gives satisfactory results. During the process, it could be observed that a small amount of non-granulated material remained on the granulator plate. The share of the sub-grain was slightly higher than in the previous sample. The share of the desired fraction is $87.2 \%$, which is a worse result than in test II, but satisfactory. Obtaining the average strength of the granulate with a grain size in a range of $1-8 \mathrm{~mm}$ above $10 \mathrm{~N}$ is also a good value. It is worth noting that reducing the mass of liquid by $100 \mathrm{~g}$ per $2000 \mathrm{~g}$ of raw material will radically reduce the costs of drying, which in the case of the granulation methods discussed constitute the majority of production costs. The comparison of the results of two-stage disc granulation with the use of $20 \%$ magnesium lignosulfonate solution and $20 \%$ molasses solution is shown in Figure 17. The tests differed in the liquid used and the weight of the liquid delivered to the bed. 


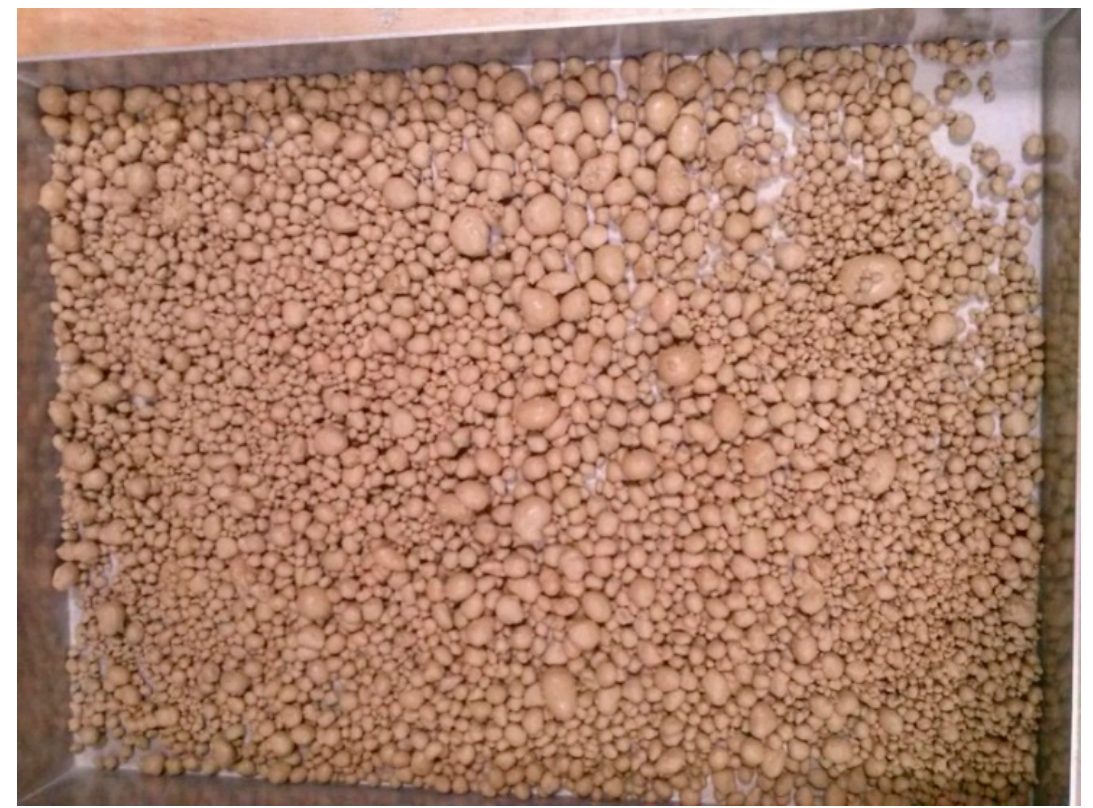

Figure 16. Material after granulation in the mixer and plate, test II.

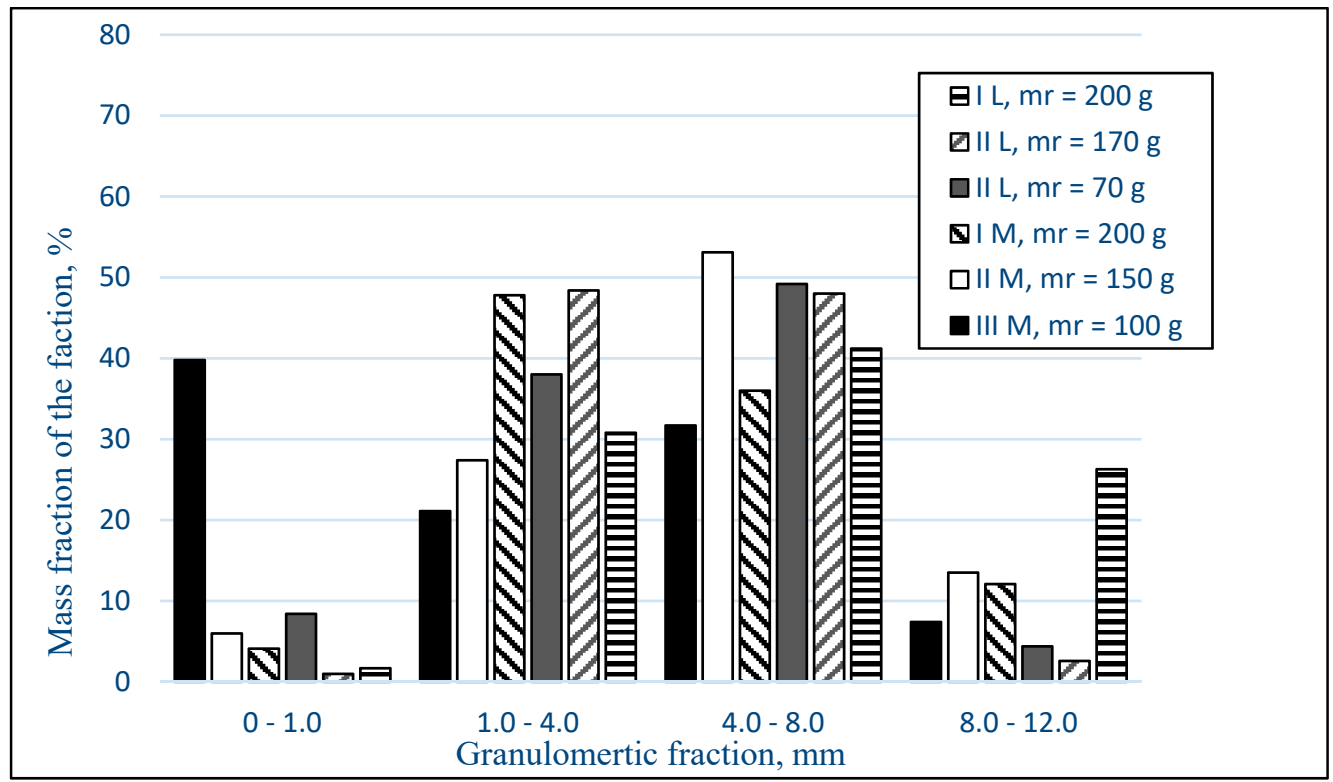

Figure 17. Comparison of the mass fractions of the granulate obtained for two-stage granulation, (mr-mass of the solution).

Where $200 \mathrm{~g}$ of the lignosulfonate solution is used, the obtained product obtained was clearly overwhelmed. The granules stuck together to form large, irregular shapes. This contributed to the high proportion of oversize grain. This was not the case with the use of $200 \mathrm{~g}$ of molasses solution. In this test, $83.8 \%$ of the beneficial fraction was obtained, and the share of oversize was $12 \%$, i.e., $14 \%$ less than in the corresponding test with the lignosulfonate solution. The trial in which $170 \mathrm{~g}$ of the lignosulfonate solution was dosed gave a product that constituted $96 \%$ of the total mass fraction. In the experiment in which $70 \mathrm{~g}$ of lignosulfonate was delivered (the weight of the binder was reduced by $100 \mathrm{~g}$ ), $87.2 \%$ of fractions $1-8$ were obtained. In both above-mentioned tests, the final product was characterized by a spherical shape. Granulating in two stages with the molasses solution used in the amount of $150 \mathrm{~g}, 80 \%$ of the beneficial fraction was obtained. The results 
presented also show that during the trial in which $100 \mathrm{~g}$ of molasses solution was used satisfactory results were not obtained. A lot of non-granulated material was produced and the proportion of fractions $1-8$ was only $52 \%$. The study of the disintegration time of granules in water showed that for all the trials carried out in the one and two-stage technology, the duration of grain disintegration in a humid environment did not exceed $8 \mathrm{~h}$. This guarantees the possibility of enriching the soil with minerals and elements that were part of the granule. In the case of calcium fertilizers, this time is required to be short, and the necessary condition for the release of soil deacidification elements is the possibility of their migration beyond the volume of the granule. This condition is met when the granulate meeting the strength requirements at the same time has the ability to disintegrate immediately after application to the soil as a result of precipitation or under the influence of moisture contained in the ground.

\subsection{Verification of the Results Obtained in Industrial Trials}

The effectiveness of the granulation method of the two-stage gypsum-lime mixture analyzed during laboratory tests was verified in an industrial installation at Nordkalk sp. $\mathrm{z}$ o. o. The test was carried out on the efficiency of the feed delivered amounting to 10,000 $\mathrm{kg} / \mathrm{h}$. The first stage was carried out in a continuous high-speed mixer granulator, the second stage was carried out in a disc granulator with a disc diameter of $2.5 \mathrm{~m}$.

The test was carried out while wetting the bed with a $20 \%$ molasses solution. After the nucleation step in the high-speed mixer (granulator), before the disc granulation, the moisture of the processed bed was $11.7 \%$. After the disc granulation and drying steps, a product with the properties shown in Tables 7 and 8 was obtained.

Table 7. Sieve analysis results, industrial test.

\begin{tabular}{cccc}
\hline \multicolumn{4}{c}{ Sieve Analysis } \\
\hline Oversize & $\mathbf{4 - 8} \mathbf{~ m m}$ & $\mathbf{1 - 4} \mathbf{~ m m}$ & Undersize \\
\hline$\%$ & $\%$ & $\%$ & $\%$ \\
\hline 4.1 & 45.8 & 46.9 & 3.2 \\
\hline
\end{tabular}

Table 8. Strength test results, industrial test.

\begin{tabular}{cccccc}
\hline \multicolumn{5}{c}{ Comparison of Granulate Strength } \\
\hline \multirow{2}{*}{ Test Name } & $\begin{array}{c}\text { Fraction, } \\
\text { mm }\end{array}$ & \multicolumn{3}{c}{ Force, $\mathbf{~}$} & $\begin{array}{c}\text { Final } \\
\text { Humidity, \% }\end{array}$ \\
\cline { 2 - 5 } $\mathrm{P}$ & $1-4$ & 14.3 & Max & Average & 2.1 \\
\cline { 2 - 5 } & $4-8$ & 34.8 & 51.8 & 28.7 & 3.6 \\
\hline
\end{tabular}

The granulate obtained divided into fractions of $1-4 \mathrm{~mm}$ and $4-8 \mathrm{~mm}$, shown in Figure 18. During granulation on an industrial scale, comparable results for granulation on a laboratory scale were obtained. The product obtained is of high strength and granulometric composition, in which the total weight of undersize and oversize is less than $10 \%$ of the total weight of the product. The concept of two-stage granulation of gypsum-lime fertilizer using liquids such as molasses or magnesium lignosulfonate has been positively verified on an industrial scale.

In the research conducted it was found that during granulation of the lime-gypsum mixture, both in the one-stage and two-stage mode, water solutions of molasses and magnesium lignosulfonate can be used interchangeably as a binder. Both liquids mentioned allow granules to be obtained with satisfactory quality parameters. It has been proven that less lignosulfonate weight (based on feed weight) can be delivered to achieve the desired effect than molasses. The use of molasses solutions is justified by the fact that it is an organic waste material from sugar production. The use of such a binder is, therefore, part 
of the philosophy of the circular economy. Moreover, the granulate produced is an organicmineral fertilizer. Proving the possibility of replacing the molasses solution with the lignosulfonate solution is of great importance due to the cases of mold growth in fertilizers containing sugar in their composition. At certain times of the year, when there is less demand for fertilizers and weather conditions directly affect the level of humidity in storage rooms, it is possible to alternatively produce fertilizer with a different composition (in an extension of the production range) that is resistant to the above-mentioned inconvenience.

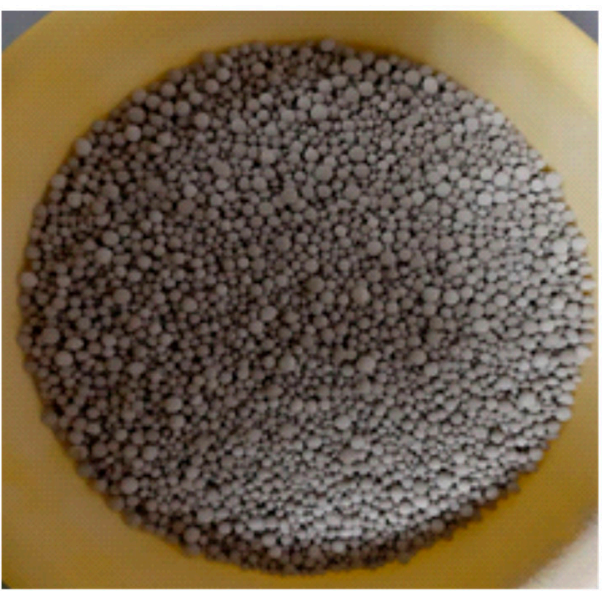

(a)

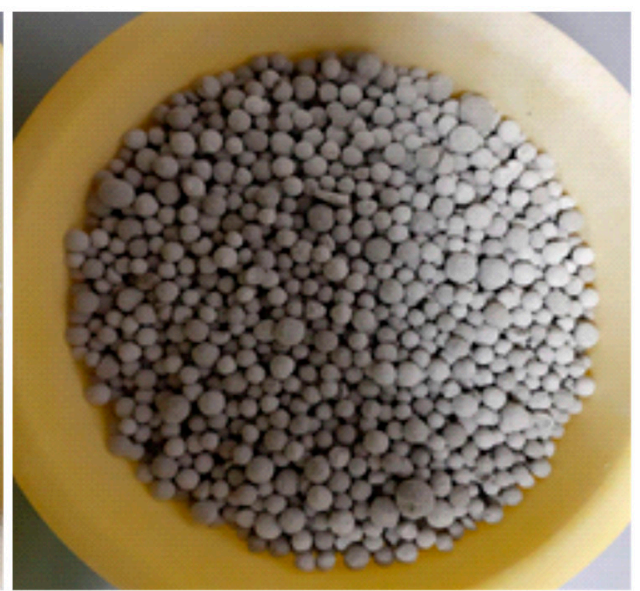

(b)

Figure 18. Granulate obtained after class III 1-4 $\mathrm{mm}(\mathbf{a})$ and $4-8 \mathrm{~mm}(\mathbf{b})$.

This study verified the two-stage method of granulation of gypsum-lime fertilizer on an industrial scale. A fertilizer granulation test was performed at the Nordkalk sp. z o. o. plant. in Sławno (Poland). The proposed concept of granulation of a two-stage gypsumlime mixture was verified in a trial with a capacity of $10,000 \mathrm{~kg} / \mathrm{h}$. The granulometric compositions obtained and the compressive strength of the fertilizer were better than the product obtained in the laboratory scale tests.

\section{Conclusions}

It is worth emphasizing that the proposed granulation methods do not dry the gypsum which is moist after the flue gas desulphurization process, thus reducing production costs. In both cases, it was found that there is an optimal quotient of the mass of the supplied liquid in relation to the mass of the processed loose material. Thus, both during onestage and two-stage granulation, it is possible to control the humidification parameters by supplying the processed bed with different masses of the moisturizing liquid. This is important as there is a high probability that the sulfogypsum received at a different time of the year or from a different supplier may have a different moisture content. Due to the method of dispensing the liquid, the operation is less problematic for the mixer granulation, where the liquid of a fixed mass (or capacity in the case of a continuous mixer) is delivered practically in one portion. In the case of disc granulation, a constant flow rate of the supplied liquid should be ensured, and the time and place of moisturizing the bed circulating in the plate should be determined. In this method, the phenomenon of wet material sticking to the camera walls is also a bigger problem. Moreover, the use of multi-stage granulation allows a product to be obtained with properties comparable to disc granulation with much lower bed moisture. This results directly from the nucleation conditions that take place in the high-speed granulator (mixer-mixer). Rotary movement of the stirrer and the granulator bowl with a relatively high rotational speed results in the formation of large inertial forces acting on the processed bed. Moist as a result of the previous processes and liquid supply, the material subjected to centrifugal force is deprived of water accumulated in the pores, which penetrates the surface of the formed 
seed granulation and, together with the delivered lignosulfonate or molasses solution, initiates the growth of nuclei and granules to the size of approximately 1-2 $\mathrm{mm}$. In the case of disc granulation-one-stage granulation, part of the water is still accumulated in the pores of the gypsum and does not support the agglomeration process. Only after compacting the resulting granules, does it suddenly flow to the surface of a few millimeter agglomerates, causing them to stick together and quickly, unfavorably, increase their size. Taking into account the above, it can be concluded that the more advantageous technology is two-stage granulation. However, the higher investment costs of such a solution should be remembered.

Summarizing the conclusions, the following sub-items can be formulated:

1. The research results allow us to state that the expected granulation effect can be obtained with each of the methods analyzed. The more advantageous method is the two-stage granulation, which allows comparable results to the one-stage granulation to be obtained, with a lower moisture content of the granulate obtained. The quality of the granulate obtained, its strength, and granulometric composition meet the operational requirements, regardless of the selected granulation technology.

2. The use of multi-stage granulation allows a product to be obtained with properties comparable to disc granulation with much lower bed moisture. This facilitates a reduction in drying costs.

3. During the granulation of the lime-gypsum mixture, molasses and magnesium lignosulfonate can be used interchangeably. In order to obtain granulate with satisfactory parameters, lower weight of lignosulfonate than molasses is needed.

4. The proposed concept of granulation of a two-stage gypsum-lime mixture has been verified on an industrial scale.

Author Contributions: Methodology, R.S., J.K., S.S., P.P., K.Ł., T.P.O., Ł.A. and R.M.; software, A.O. and T.P.O., K.S.; validation, K.Ł., S.S., A.O., R.M., K.S. and R.S.; formal analysis, R.M., A.O. and J.K.; investigation, S.S., R.M. and A.O.; resources, S.S., A.O., R.M. and T.P.O.; data curation, K.Ł., A.O., S.S., Ł.A. and T.P.O.; writing—original draft preparation, A.O. and T.P.O.; writing-review and editing, A.O., T.P.O., R.S. and J.K.; visualization, A.O., K.S.; supervision, S.S., K.Ł., A.O., Ł.A. and T.P.O.; project administration, A.O. and S.S.; funding acquisition, A.O. and S.S. All authors have read and agreed to the published version of the manuscript.

Funding: This work was supported by the Ministry of Science and Higher Education (grant No. 501/10-34-1-7015 and No. 501/15/30/1/9157). The studies presented were financed by the National Center of Research and Development (NCBR) Poland under the research program LIDER. The research and development project is entitled by the acronym BIOCARBON, with the title "Modern technology biomass torrefaction process to produce fuel mixtures, biocoal as additives for fertilizers, activated carbon for energy sector, agriculture, civil engineering and chemical industry", "LIDER IX" NCBR 2014-2020 (grant no. 0155/L-9/2017).

Conflicts of Interest: The authors declare no conflict of interest.

\section{References}

1. Kapur, P.C.; Fuerstenau, D.W. Size distributions and kinetic relationships in the nuclei region of wet pelletization. Process Des. Dev. 1966, 5, 5-10. [CrossRef]

2. Sastry, K.V.S.; Fuerstenau, D.W. Mechanisms of agglomerate growth in green pelletization. Powder Technol. 1973, 7, 97-106. [CrossRef]

3. Ennis, B.J.; Litster, J.D. Particle size enlargement. In Perry's Chemical Engineers' Handbook, 7th ed.; Perry, R., Green, D., Eds.; McGraw-Hill: New York, NY, USA, 1997; pp. 20.56-20.89.

4. Litster, J.D.; Ennis, B.J.; Lian, L. The Science and Engineering of Granulation Processes; Kluwer Academic Publishers: Dordrecht, The Netherlands; Boston, MA, USA, 2004.

5. Tardos, G.I.; Irfan-Khan, M.; Mort, P.R. Critical parameters and limiting conditions in binder granulation of fine powders. Powder Technol. 1997, 94, 245-258. [CrossRef]

6. Iveson, S.M.; Litster, J.D.; Hapgood, K.; Ennis, B.J. Nucleation, growth and breakage phenomena in agitated wet granulation processes: A review. Powder Technol. 2001, 117, 3-39. [CrossRef] 
7. Obraniak, A.; Gluba, T. The effect of disaccharide concentration in a liquid binder on the mechanisms and kinetics of disc granulation. Chem. Process Eng. 2017, 38, 295-306. [CrossRef]

8. Siuda, R.; Kwiatek, J.; Obraniak, A.; Gluba, T.; Olejnik, T.P.; Marszałek-Gubiec, M.; Pietrasik, T. Comparison of granulation methods of lime-gypsum fertilizer. Przem. Chem. 2018, 97, 1550-1553.

9. Szufa, S.; Piersa, P.; Adrian, Ł.; Sielski, J.; Grzesik, M.; Romanowska-Duda, Z.; Piotrowski, K.; Lewandowska, W. Acquisition of torrefied biomass from Jerusalem artichoke grown in a closed circular system using biogas plant waste. Molecules 2020, $25,3862$. [CrossRef]

10. Olejnik, T.P. Kinetics of grinding ceramic bulk considering grinding media contact points. Physicochem. Probl. Miner. Process. 2010, 44, 187-194.

11. Olejnik, T.P. Analysis of the breakage rate function for selected process parameters in quartzite milling. Chem. Process Eng. 2012, 33, 117-129. [CrossRef]

12. Lawinska, K.; Wodzinski, P.; Modrzewski, R. A method for determining sieve holes blocking degree. Physicochem. Probl. Miner. Process. 2015, 51, 15-22.

13. Lawinska, K.; Modrzewski, R.; Serweta, W.G. The phenomenon of screen blocking for mixtures of varying blocking grain content. Miner. Resour. Manag. 2018, 34, 83-95.

14. Kwiatek, J.; Siuda, R.; Gluba, T.; Olejnik, T.P.; Obraniak, A.; Marszałek-Gubiec, A.; Pietrasik, T. Granulation of limestone powder with selected binding liquids. Przem. Chem. 2018, 97, 1542-1548.

15. Harrison, C.P.; Tittle, C.G. Agglomeration of Gypsum, Limestone, or Gypsum-Limestone Mix. U.S. Patent 4954134A, 4 September 1990.

16. Gluba, T.; Obraniak, A.; Siuda, R.; Kwiatek, J. A Method of Producing Single or Multi-Component Granulated Calcium and/or Calcium-Magnesium. Fertilizer. Patent RP 231028, 14 September 2018.

17. Ławińska, K.; Szufa, S.; Obraniak, A.; Olejnik, T.; Siuda, R.; Kwiatek, J.; Ogrodowczyk, D. Disc granulation process of carbonation lime mud as a method of post-production waste management. Energies 2020, 13, 3419. [CrossRef]

18. Greinert, A.; Mrówczyńska, M.; Szefner, W. Study on the possibilities of natural use of ash granulate obtained from the combustion of pellets from plant biomass. Energies 2019, 12, 2569. [CrossRef]

19. Szufa, S.; Wielgosiński, G.; Piersa, P.; Czerwińska, J.; Dzikuć, M.; Adrian, Ł.; Lewandowska, W.; Marczak, M. Torrefaction of straw from oats and maize for use as a fuel and additive to organic fertilizers-TGA analysis, kinetics as products for agricultural purposes. Energies 2020, 13, 2064. [CrossRef]

20. Szufa, S. Use of superheated steam in the process of biomass torrefaction. Przemyst Chem. 2020, 99, 1797-1801. [CrossRef]

21. Dzikuć, M.; Kuryło, P.; Dudziak, R.; Szufa, S.; Dzikuć, M.; Godzisz, K. Selected aspects of combustion optimization of coal in power plants. Energies 2020, 13, 2208. [CrossRef]

22. Gluba, T.; Obraniak, A. Nucleation and granule formation during disc granulation process. Physicochem. Probl. Miner. Process. 2012, 48, 113-120.

23. Behjani, M.A.; Rahmanian, N.; Fardina, N.; Ghani, A.; Hassanpour, A. An investigation on process of seeded granulation in a continuous drum granulator using DEM. Adv. Powder Technol. 2017, 28, 2456-2464. [CrossRef]

24. Li, H.; Zhang, J.; Zheng, W.; Cui, T.; Yang, Y. Study on the properties and process parameters of different clays in disc granulation. Materials 2020, 13, 1714. [CrossRef]

25. Gluba, T.; Olejnik, T.P.; Obraniak, A. Technology for producing washing agent in continuous process. Przem. Chem. 2015, 94, 1370-1374.

26. Feliks, J. Granulation of dolomite and limestone in the vibratory granulator. Przem. Chem. 2015, 94, 771-773.

27. Knight, P.C. An investigation of the kinetics of granulation using a high shear mixer. Powder Technol. 1993, 77, 159-169. [CrossRef]

28. Kaur, G.; Singh, M.; Kumar, J.; de Beer, T.; Nopens, I. Mathematical modelling and simulation of a spray fluidized bed granulator. Processes 2018, 6, 195. [CrossRef]

29. Neugebauer, C.; Bück, A.; Palis, S.; Mielke, L.; Tsotsas, E.A.; Kienle, A. Influence of thermal conditions on particle properties in fluidized bed layering granulation. Processes 2018, 6, 235. [CrossRef]

30. Adrian, Ł.; Piersa, P.; Szufa, S.; Romanowska-Duda, Z.; Grzesik, M.; Cebula, A.; Kowalczyk, S.; Ratajczyk-Szufa, J. Experimental research and thermographic analysis of heat transfer processes in a heat pipe heat exchanger utilizing as a working fluid R134A. In Renewable Energy Sources: Engineering, Technology, Innovation; Springer: Berlin/Heidelberg, Germany, 2018 ; pp. 413-421.

31. Wildeboer, W.J.; Litster, J.D.; Cameron, I.T. Modelling nucleation in wet granulation. Chem. Eng. Sci. 2005, 60, 3751-3761. [CrossRef]

32. Heim, A.; Gluba, T.; Obraniak, A. The effect of the wetting droplets size on power consumption during drum granulation. Granul. Matter 2004, 6, 137-143. [CrossRef]

33. Heim, A.; Kaźmierczak, R.; Obraniak, A. Model dynamiki złoża ziarnistego w granulatorze talerzowym. Chem. Process Eng. 2004, 25, 993-998.

34. Kl, K.E.; Ileleji, Y.; Li, R.P.K.; Ambrose, P.H. Doane experimental investigations towards understanding important parameters in wet drum granulation of corn stover biomass. Powder Technol. 2016, 300, 126-135.

35. Schaafsma, S.H.; Vonk, P.; Segers, P.; Kossen, N.W.F. Description of agglomerate growth. Powder Technol. 1998, 97, 183-190. [CrossRef]

36. Kryszak, D.; Bartoszewicz, A.; Szufa, S.; Piersa, P.; Obraniak, A.; Olejnik, T.P. Modeling of Transport of Loose Products with the Use of the Non-Grid Method of Discrete Elements (DEM). Processes 2020, 8, 1489. [CrossRef] 
37. Stelmach, J.; Kuncewicz, C.; Szufa, S.; Jirout, T.; Rieger, F. The Influence of Hydrodynamic Changes in a System with a Pitched Blade Turbine on Mixing Power. Processes 2021, 9, 68. [CrossRef]

38. Baiming, R.; Yaqian, Z.; Bin, J.; Ting, W.; Cheng, S. granulation of drinking water treatment residues: Recent advances and prospects. Water 2020, 12, 1400.

39. Obraniak, A. Effect of potato starch solution on the disc granulation mechanisms. Przem. Chem 2017, 96, 2339-2343.

40. Obraniak, A.; Orczykowska, M.P.; Olejnik, T.P. The effects of viscoelastic properties of the wetting liquid on the kinetics of the disc granulation process. Powder Technol. 2019, 342, 328-334. [CrossRef]

41. Boenkendorf, U.; Stumpf, T.; Lange, C.; Ernst, N. Producing Lime- or Dolomite Containing Agglomerate, Useful e.g. as a Fertilizer, a Supplement Agent in Metallurgy, Comprises Building-Up Agglomeration with Finely Divided Solid Starting Materials and a Liquid Agglomeration. Medium. Patent DE102009053210, 6 November 2009.

42. Zhalehrajabi, E.; Lau, K.K.; Zilati, K.; Shaari, K.; Mojib, S.; Seyedin, H.Z.; Azeem, B.; Shaaban, A. Effect of biodegradable binder properties and operating conditions on growth of urea particles in a fluidized bed granulator. Materials 2019, 12, 2320. [CrossRef]

43. Czarnota, J.; Tomaszek, J.A.; Masłon, A.; Piech, A.; Łagód, G. Powdered ceramsite and powdered limestone use in aerobic granular sludge technology. Materials 2020, 13, 3894. [CrossRef]

44. Blaszczyk, M.; Heim, A.; Olejnik, T.P. The effect of wetting on the course of the drum granulation. Chem. Process Eng. 2017, 38, 331-342. [CrossRef]

45. Gluba, T.; Obraniak, A.; Siuda, R.; Kwiatek, J. The Method of Producing Granulated Calcium Fertilizer. Patent RP 231025, 14 September 2018.

46. Gluba, T.; Obraniak, A.; Siuda, R.; Kwiatek, J. The Method of Producing Granulated Calcium Fertilizer. Patent RP 231026, 14 September 2018.

47. Gluba, T.; Obraniak, A.; Siuda, R.; Kwiatek, J. A Method of Producing Single or Multi-Component Granulated Calcium and/or Calcium-Magnesium Fertilizer. Patent RP 231027, 14 September 2018.

48. Obraniak, A.; Stelmach, J.; Olejnik, T.P. Description of the shapes of water drops in the initial phase of falling. Przem. Chem. 2019, $98,751-756$.

49. Obraniak, A.; Stelmach, J.; Olejnik, T.P.; Glogowski, M. Analysis of droplet formation in nozzles used in granulation processes. Przem. Chem. 2018, 97, 258-262. 